\title{
Attenuation of spatial memory in 5xFAD mice by targeting cholinesterases, oxidative stress and inflammatory signaling using 2-(hydroxyl-(2-nitrophenyl)methyl)cyclopentanone
}

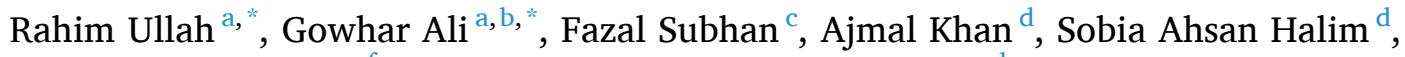 \\ Muhammad Naveed ${ }^{\mathrm{e}, \mathrm{f}}$, Saima Kalsoom ${ }^{g}$, Ahmed Al-Harrasi ${ }^{\mathrm{d}}$ \\ ${ }^{a}$ Department of Pharmacy, University of Peshawar, Peshawar 25120, Pakistan \\ ${ }^{\mathrm{b}}$ The Ken and Ruth Davee Department of Neurology and Clinical Neurosciences, Northwestern University Feinberg School of Medicine, Tarry Building, Room 13-715, \\ 300 East Superior St., Chicago, IL 60611, United States \\ ${ }^{\mathrm{c}}$ Department of Pharmacy, CECOS University of Science and technology, Peshawar, Pakistan \\ ${ }^{\mathrm{d}}$ Natural and Medical Sciences Research Center, University of Nizwa, Birkat-ul-Mouz 616, Nizwa, Sultanate of Oman \\ ${ }^{\mathrm{e}}$ Department of Pharmacology and Pharmacotherapy, Faculty of Medicine, University of Szeged, Szeged, Hungary \\ ${ }^{\mathrm{f}}$ Department of Pharmacy, Faculty of Biological Sciences, Quaid-i-Azam University, Islamabad, Pakistan \\ ${ }^{\mathrm{g}}$ Center for Interdisciplinary Research in Basic Sciences (CIRBS), International Islamic University, Islamabad, Pakistan
}

\section{A R T I C L E I N F O}

\section{Keywords:}

2-(hydroxyl-(2-nitrophenyl)methyl)

cyclopentanone

Alzheimer disease

Cholinesterase

Antioxidants

Neuroinflammation

Cognitive deficits

\begin{abstract}
A B S T R A T
Alzheimer's disease (AD) is classified pathologically as a progressive neurological disorder associated with memory decline. The study was designed to assess the underlying molecular signaling involved in the neuroprotective effect of the 2-(hydroxyl-(2-nitrophenyl)methyl)cyclopentanone (2NCP) as a novel therapeutic agent for $\mathrm{AD}$. In this connection, in vitro cholinesterases inhibitory and antioxidant activities were investigated. In vivo studies were carried out on a well-known 5xFAD mice model in different behavioural models such as light/dark box,balance beam, rotarod, elevated plus maze (EPM),novel object recognition (NOR), paddling Y-maze, and Morris water maze (MWM) tests. Hippocampus (HC) and frontal cortex (FC) homogenates were examined for acetylcholinesterase ( $A C h E$ ) and butyrylcholinesterase (BChE) activities, 1,1-diphenyl-2-picrylhydrazyl (DPPH) free radicals, glutathione S-transferase (GST), glutathione (GSH), and catalase. Further, we examined the expression of inflammatory cytokines and Nrf2 in the HC and FC through RT-PCR. Computational studies were conducted to predict the binding mode of the 2NCP with target sites of nuclear factor- $\mathrm{\kappa B}(\mathrm{NF}-\mathrm{\kappa B})$ and cholinesterases. The findings of in vitro assays revealed that the $\mathrm{IC}_{50}$ values of the $2 \mathrm{NCP}$ against AChE and $B C h E$ were 17 and $23 \mu \mathrm{g} / \mathrm{ml}$ respectively. DPPH antioxidant assay displayed an IC 50 value for the $2 \mathrm{NCP}$ was $62 \mu \mathrm{g} / \mathrm{ml}$. Whereas, theex vivo study depicted that the activities of $A C h E$ and $B C h E$ were significantly reduced. Moreover, free radicals load, GSH level, catalase and GST activities were significantly declined. Furthermore, in vivostudies showed that the 2NCP treated animals exhibited gradual memory improvement and improved motor functions. RT-PCR study revealed that mRNA levels of the inflammatory mediators (IL-1 $\beta$, IL-6, TNF- $\alpha$ ) were significantly reduced, while the expression of antioxidant Nrf2 was significantly increased.The molecular docking studies further confirmed that the 2NCP showed excellent binding affinities for NF- $\mathrm{BB}$ and cholinesterases. Taken together, the $2 \mathrm{NCP}$ improves spatial memory and learning, short- and long-term memory,markedly inhibits cholinesterases, reduced neuroinflammation, and mitigated oxidative stress in the $5 x F A D$ mice; hence the $2 \mathrm{NCP}$ may be a potential candidate for the management of $\mathrm{AD}$.
\end{abstract}

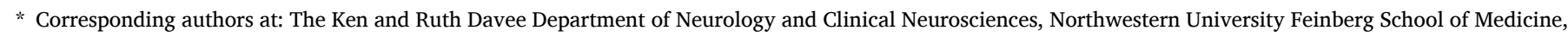

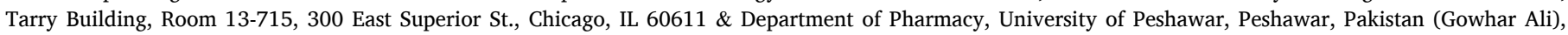
Department of Pharmacy, University of Peshawar, Peshawar, Pakistan (Rahim Ullah).

E-mail addresses: Rphrahimullah@gmail.com, Rphrahimullahstd@uop.edu.pk (R. Ullah), gowhar_ali@uop.edu.pk, gohar.pharmacist@gmail.com (G. Ali). 


\section{Introduction}

Alzheimer's disease (AD) is one of the most prevalent and progressive dementing disorder in the elderly and affects those brain areas that control memory, thoughts, language, and adversely affects the quality of life of the patients[1]. Different etiological pathways have been reported to detect $\mathrm{AD}$. These pathways include the level of cholinesterases and beta-amyloid (A $\beta$ ) proteins, cerebral blood flow, neurotransmitter fluctuations, neuroinflammation, and the development of oxidative stress [2-3]. In AD, impairment of cholinergic functions in brain areas such as the hippocampus and neocortex occur which are dealing with memory, behavior, learning, and emotional responses. Acetylcholine (ACh) level decreases in the brain of $\mathrm{AD}$ individuals. Acetylcholinesterase (AChE) and butyrylcholinesterase $(B C h E)$ enzymes are responsible for the hydrolysis of acetylcholine[4]. Hence, inhibition of these enzymes has been reported as critical targets in the treatment of $\mathrm{AD}$, leading to an increase in the level of ACh in brain areas [5]. Oxidative stress plays a key role in the pathogenesis of $\mathrm{AD}$, characterized by an imbalance between the free radicals production rate and the anti-oxidant defense system of the body [6-7]. Free radicals are associated with Alzheimer's disease, cause neuronal damage and death [8-9]. The inflammatory activity of macrophages, neutrophils, and by-products of mitochondrial electron transport chain reactions are sources of free radicals. Reactive oxygen species (ROS) such as hydrogen peroxide, superoxide anion, and hydroxyl ions produced during normal metabolic reactions as a byproduct. These ROS adversely affect the cell membrane; decrease the fluidity of the membrane, and causing loss of structural and functional capability of the membrane. Such changes have been observed in many diseases including AD [10-11]. Antioxidants scavenge free radicals by neutralizing their activities [12-13]. Nuclear factor-erythroid 2 related factor 2 (Nrf2) is a transcription factor that causes protection against free radicals by regulating the antioxidant/detoxification genes expression, that can alleviate oxidative stress neurotoxicity [14].

Chronic neuroinflammationhas been described that it causes loss of neurons in neurodegenerative diseases including AD [15-17]. Literature studies have revealed that excessive or chronic inflammation mediated by activated microglia, pro-inflammatory cytokines, and several oxidative stress entities, such as glutamate, ROS, and nitric oxide (NO) are deleterious to AD brain tissues. Pro-inflammatory cytokines such as IL$1 \beta$, IL- 6 , and TNF- $\alpha$, released by over-activated microglia, activate the surrounding astrocytes, which may act on neurons directly to induce synaptic dysfunction or apoptosis [18-19]. During progressive neuroinflammation, intracellular signaling cascades including nuclear factor$\kappa \mathrm{B}(\mathrm{NF}-\mathrm{\kappa B})$ become activated which induces the expression of various inflammatory cytokines[20].The over-expressed cytokines initiate an over activated response to inflammation which may lead to chronic neuronal damage [21-22]. Unfortunately, efficient therapy for AD is still lacking, hence, the search for more effective synthetic anti-AD compounds with anti-cholinesterase, anti-oxidant, and anti-inflammatory properties is need of the day.

Effective pharmacotherapeutic management of $\mathrm{AD}$ will reduce the burden on the health care system of the country, both in terms of cost and health. Currently, for the treatment of $\mathrm{AD}$, five drugs are used in clinical setup, containing four acetylcholinesterase inhibitors (galanthamine, rivastigmine, tacrine, and donepezil) and NMDA receptor antagonist, memantine. These drugs provide symptomatic relief to $\mathrm{AD}$ patients [23] .

The $\beta$-hydroxy ketone derivative; 4-([1,1'-biphenyl]-3-yl)-1-(benzyl (2-(2-methoxyphenoxy)ethyl)amino)-4-hydroxybutan-2-one inhibit acetylcholinesterase, confirmed by docking and in vitro studies [24]. Ketone bodies have the potential to ameliorate $\mathrm{AD}$, amyotrophic lateral sclerosis, stroke, traumatic brain injury, and Parkinson's disease [25-26]. $\beta$-hydroxy ketone derivatives; 2-(hydroxyl-3-nitrophenyl) methyl)cyclopentanone and 2-(hydroxyl-(4-nitrophenyl)methyl)cyclopentanone were tested in our lab, finding of these studies showed significant inhibition of cholinesterases, oxidative stress, reduced plaques in the HC and FC, and improved memory in 5xFAD mice [27-28]. There is no effective drug in the market to treat $\mathrm{AD}$, hence, across the globe research is going on to find out therapeutically effective drugs for this disease. Also, there are many limitations in currently available $A C h E$ inhibitors like cost and effectiveness, etc[29]. Moreover, it has been reported that the ketone bodies, aldol adducts, and their derivatives have the potential to relieve neurodegenerative disorders (Wood et al. 2018), in the same perspective we have selected 2-(hydroxyl-(2-nitrophenyl)methyl)cyclopentanone (2NCP) (Fig. 1) as a possible potential candidate against $\mathrm{AD}$. Indeed, the real promise of metabolic/ketogenic approaches is that by altering cellular energy, oxidative stress, and inflammation, ketogenic (and possible 2NCP) have the potential to do more than provide symptomatic relief but also have the potential to alter disease trajectory. The $2 \mathrm{NCP}$ has a nitrophenyl group, and literature studies revealed that compounds containing nitrophenyl groups have the potential to inhibit $A C h E, B C h E$, monoamine oxidase-B (MAO-B), and relieve oxidative stress [30]. Whereas, the nitrobenzaldehyde derivatives exhibited antioxidant activity due to the nitro group attached to the benzene ring [31-32]. The 2NCPwas synthesized by the previously reported method [33-34].

In this regard, the neuroprotective potential of the $2 \mathrm{NCP}$ was assessed in the $5 x F A D$ mice along with short- and long-term memory, spatial memory, and anxiety. Furthermore, attempts were made to investigate the potential mechanisms of the $2 \mathrm{NCP}$ neuroprotective effect, for this purpose, the level/activities of the $A C h E$ and $B C h E$, catalase, GST, GSH, inflammatory mediators (IL-1 $\beta$, IL-6, TNF- $\alpha$ ), and Nrf2 wereevaluated in the hippocampus and frontal cortex. Moreover, the computational study was carried out to predict the binding mode of the 2NCP with cholinesterases and NF-kB.

\section{Materials \& methods}

\subsection{Materials}

Acetylcholinesterase (Electric eel), butyrylcholinesterase (equine serum), acetylthiocholine iodide, butyrylthio-choline Iodide, 5,5-dithiobis-nitrobenzoic acid (DTNB), galanthaminehydrobromide, 1,1diphenyl-2-picrylhydrazyl (DPPH), hydrogen peroxide $\left(\mathrm{H}_{2} \mathrm{O}_{2}\right)$, trichloroacetic acid (TCA), sodium citrate, glutathione-S-transferase (GST), 1-chloro-2, 4-dinitrobenzene, EDTA, boric acid, agarose, and ethidium bromide were obtained from Sigma-Aldrich USA. DNA extraction kit (Novel Genomic DNA Mini Kit), TRI-reagent (Bioshop, Canada), Tris (Scharlu Spain), cDNA synthesis kit (ABM, Canada), PCR primers (Macrogen Korea) were used. PCR Master Mix and Taq polymerase were obtained from Thermo Fisher Scientific US. DNA Ladder, dNTPs, magnesium chloride were purchased from Invitrogen US, while ethanol, isopropanol, and chloroform were obtained from Merck Germany.

\subsection{In vitro assays}

\subsubsection{Acetylcholinesterase and butyrylcholinesterase inhibition assays}

Cholinesterases inhibition assay of the $2 \mathrm{NCP}$ was carried out following standard Ellman's assay. Acetylthiocholine iodide and butyrylthiocholine iodide were used as substrates. Degradation of these substrates leads to the formation of 5-thio-2-nitrobenzoate, which forms a

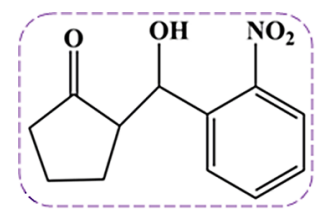

Fig. 1. Chemical structure of the 2-(hydroxy-(2-nitrophenyl)methyl) cyclopentanone. 
yellow color complex with DTNB, which was assayed through microplate reader at $412 \mathrm{~nm}$ wavelength [35].

The rate of absorbance $(\mathrm{V}=\Delta A B / \Delta t)$ showed the \%-enzyme activity and inhibition by the test and control samples and was calculated as follows,

$\%$-Enzyme inhibition $=100$-enzyme activity $(\%)$

$\%$-Enzyme activity $=100 \times \mathrm{V} / \mathrm{Vmax}$

Vmax shows the maximum enzyme activity in the absence of inhibitory agent.

\subsubsection{DPPH scavenging assay}

The DPPH radical assay was conducted following reported protocol with slight modifications [36]. Following this method, $0.024 \%$ solution of DPPH and $0.1 \%$ stock solutions of control and test drugs were prepared in methanol. The stock solution of the test drugs was further diluted to different concentrations, and $0.1 \mathrm{ml}$ of these diluted solutions was added to the DPPH solution in microplate-reader (96 wells) and the absorbance was measured at $517 \mathrm{~nm}$.

\subsection{In vivo activities}

\subsubsection{Animals}

In vivo studies were conducted in the $5 \mathrm{xFAD}$ mouse model of Alzheimer's disease, sub-strain of Jax strain006554, MMRRC034840 B6SJL-Tg (APPSwFILon, PSEN1* M146L*L286V) 6799Vas/Mm obtained from Jackson laboratory US. A letter of permission has been obtained from Jackson laboratory, to utilize these animals for research purposes. 5xFAD mice of either sex (age: 5-6 months) were used as a disease group and wild-type mice littermates were used as a control group. Animals were bred and kept at $22 \pm 2{ }^{\circ} \mathrm{C}$ with $12 / 12 \mathrm{~h}$ light/dark cycle in the animal house at the Department of Pharmacy, University of Peshawar, Pakistan.

\subsubsection{Research ethical approval}

Departmental research ethical committee of the University of Peshawar has approved all experimental procedures on animals vides a reference number 12/EC-17/Pharm, dated. 24/05/2017. All experiments were carried out according to the Animals' Scientific Procedures Act, 1986.

\subsubsection{Animal grouping and route of drug administration}

In this study, animals were divided into six groups $(n=10)$.

Group I: Wild type (WT) mice

Group II: 5xFAD transgenic mice

Group III: 5xFAD-galanthamine ( $8 \mathrm{mg} / \mathrm{kg}$, i.p)

Group IV: 5xFAD $-2 \mathrm{NCP}(10 \mathrm{mg} / \mathrm{kg}$ i.p)

Group V: 5xFAD -2NCP (20 mg/kg i.p)

Group VI: 5xFAD -2NCP (40 mg/kg i.p)

Galanthamine and 2NCP were dissolving in vehicle containing DMSO, Tween-80, and normal saline in a ratio of 5:2:93. Animals were treated with vehicle/galanthamine/2NCP for 28 days.

\subsubsection{Genotyping of transgenic mice}

The methodology of genotyping specified by Jackson lab U.S for strain transgenic mice was followed with slight modifications [27]. DNA extraction was carried out using a DNA extraction kit following the manufacturer's protocol. Two sets of primers were used in genotyping:

Internal positive control; F, 5'-CTAGGCCACAGAATTGAAAGATCT$3^{\prime}$,

R, 5'-GTAGGTGGAAATTCTAGCATCATCC-3' and Transgene F, 5'AGGACTGACCACTCGACCAG-3', R, 5'-CGGGGGTCTAGTTCTGCAT-3'.

The annealing temperature was $55^{\circ} \mathrm{C}$ for $60 \mathrm{sec}$. PCR products were identified through gel electrophoresis; amplified products were visualized using a UV trans-illuminator.

\subsubsection{Light/Dark box (LD) test}

The light dark box (LD) test is commonly used to evaluate the anxiety status of rodents. The LD box consisted of two compartments; light and dark compartments, with an opening between two compartments. The mouse was placed in the light compartment and allowed freely to explore the apparatus for $5 \mathrm{~min}$, the time latency to enter the dark compartment and the time spent in the light compartment were observed [37-38].

\subsubsection{Balance beam test}

The balance beam is made up of a large wood/tube lined with soft foam to minimize animal injuries. The starting side was luminous while the ending side was darker. Animals were trained one day before starting the test trial to reduce neophobia. Animals were administered respective drugs and $1 \mathrm{~h}$ after drug administration; the animal was placed at the luminous ending and allowed to cross the beam. The time of crossing the beam was recorded [39].

\subsubsection{Rotarod test}

Rotarod test is used to assess the motor coordination deficits [40]. Animals were trained for two days, four trials each day. Each mouse was placed on the accelerating rod (4-40 rpm) for $5 \mathrm{~min}$. On the next day after training trials, test trials were carried out and the falling latency time was recorded.

\subsubsection{Elevated plus maze (EPM)}

Elevated plus maze is a plus-shaped apparatus consisting of two open and two closed arms lying at a right angle to each other with a central platform. The time taken by mice to enter from the open-arm into the close arm is transfer latency time, which was noted. In-order to habituate the mice with the maze, mice were trained one day before the commencement of the test, each animal was kept at one end of the open arms and allowed to enter to the close arms, after $10 \mathrm{~s}$ stay in close arm returned to the home cage. The animal failed to enter into the close arm within $120 \mathrm{~s}$, manually guided to enter into the close arm. The above procedure was repeated after $24 \mathrm{~h}$ to examine the withholding of memory [28].

\subsubsection{Novel object recognition (NOR) test}

The NOR test is commonly used to assess the learning and memory [41]. This test was performed in the open field apparatus as described for open field test following previously reported method [42]. Each mouse was habituated to the apparatus by placing in the empty box without any object for $10 \mathrm{~min}$. Mice were trained for $5 \mathrm{~min}$ after habituation phase by placing in the apparatus containing two similar objects. Each animal was tested for the assessment of short term and long term memory at $2 \mathrm{hr}$ and $24 \mathrm{hr}$ after the training trial, the animal was placed in the box and allowed to explore the apparatus for $5 \mathrm{~min}$. During the test trial, one of the objects was replaced with a novel object having different shape. Also one of the objects was replaced with another new object during long term memory testing carried out $24 \mathrm{hr}$ after the training trial. Exploration was defined as touching or sniffing the object or head orienting towards the object. The time that the mice spent exploring each object during both test trials was recorded and the discrimination index was calculated as; Discrimination index (DI) = time of exploring the novel object/total time of exploration $\times 100 \%$

\subsubsection{Y-Maze (Paddling) test}

Animals of each group were trained for three days with 3 trials each day, one hour apart from each other. The animal was placed in one of the close arms ends at the beginning of each trial. The arms selection was made with semi-random series of the starting position and three successive trails were performed at the same position. The time duration for each trial was $60 \mathrm{~s}$ and the mice that failed to find the exit hole within 60 $\mathrm{s}$ were guided manually to the open end via a transparent slide. In the test trial, animals were subjected to the Y-Maze apparatus for five days 
and escape latency time was recorded each day. Spontaneous alternation behavior (SAB) was observed on day 5 of the test trials by placing each mouse at the center of the Y-Maze apparatus and allowed to move freely through the apparatus for 3 sessions (each session of eight min). The numbers of arm-entries were recorded [39].

The percent alternation behavior was calculated using the following formula;

Alternationbehavior $(\%)=\frac{\text { Numberofalternations }}{\text { totalnumberofarmentries }-2} \times 100$

\subsubsection{Morris water maze (MWM)}

The effect of the 2NCP on the spatial learning and memory of the transgenic $5 \mathrm{xFAD}$ mice was investigated through the MWM apparatus containing opaque water maintained at $22-23{ }^{\circ} \mathrm{C}$, according to the reported method with minor modification [43-44]. The maze comprises four quadrants with a hidden platform set $1 \mathrm{~cm}$ below the water surface in one of these quadrants. All animals were trained for 5 days continuously (4 trials/day). The escape latency time in seconds to find the submerged platform was observed. The mice which failed to find out the hidden-platform in one minute were guided manually and allowed to stay on the platform for $10 \mathrm{~s}$. After training, the animals were tested for memory retention in the probe trial on day 6 . The probe trial was carried out without a platform for one minute. The time duration spent by mice in the target quadrant and the number of platform area crossings were noted. An overhead camera was used for recording the experimental activities.

\subsection{Ex vivo assays}

\subsubsection{Evaluation of cholinesterase inhibition in the hippocampus and frontal cortex}

This assay was carried out following standard protocol. All animals of each group were killed by decapitation at the end of behavioral experiments under ether anesthesia. In ice-cold $0.1 \mathrm{M}$ phosphate saline buffers (pH 8.0), HC and FC were dissected and homogenized, the supernatant was used for the $A C h E$ and $B C h E$ assay $[35,45]$. Thiocholine and acetate thiocholine form after degradation of acetylcholine and butyrylcholine, which combined with DNTB and produced a yellow complex, this complex was assayed by absorbance at $412 \mathrm{~nm}$ in a microplate reader [46].

\subsubsection{Glutathione S-transferase (GST), glutathione (GSH) and catalase assay}

The activities or level of catalase, GST, and GSH in the hippocampus and frontal cortex were determined following Ellman's method. Hippocampal and frontal cortex tissues were homogenized and centrifuged at speed of $1000 \times \mathrm{g}$ at $4{ }^{\circ} \mathrm{C}$ for $15 \mathrm{~min}$, the supernatant was used in this assay. The enzymes (GST and catalase) activities and GSH level were determined by observing the variation in absorbance via microplate reader at specific wavelengths $(240,340$, and $420 \mathrm{~nm})$ [47-48].

\subsubsection{DPPH scavenging assay of the hippocampus and frontal cortex}

The DPPH free radical scavenging activity was carried out following the previously reported method [49]. The hippocampus and frontal cortex tissues of all animals were homogenized in $1 \mathrm{ml}$ methanol $(0.1$ $\mathrm{mg} / \mathrm{ml}$ ) with succeeding addition of $400 \mu \mathrm{l}$ of DPPH solution $(0.1 \mathrm{mM})$. These solutions were maintained at $37{ }^{\circ} \mathrm{C}$ for $30 \mathrm{~min}$ and absorbance was measured using a microplate-reader at $517 \mathrm{~nm}$. The inhibition in percent of DPPH free radicals was determined using the following formula:

DPPHinhibition $(\%) \frac{A B c-A B s}{A B c} \times 100$

Where $\mathrm{AB}$ denotes absorbance, $\mathrm{c}$ denotes to control and $\mathrm{s}$ indicate sample.

\subsection{Reverse transcriptase-PCR (RT-PCR)}

Total RNA was extracted from mice hippocampus and frontal cortex according to the manufacturer's protocol using TRI-reagent and purity of total RNA was determined using a UV spectrophotometer. Total RNA was transcribed to cDNA using a cDNA synthesis kit. The expression of targeted genes was determined. Sequences of targeted genes are;

IL-1 $\beta$; forward 5'-AGAAGCTTCCACCAATACTC-3', reverse $5^{\prime}$ AGCACCTAGTTGTAAGGAAG-3'

IL-6; forward 5'-GCCCTTCAGGAACAGCTATGA-3', reverse $5^{\prime}$ TGTCAACAACATCAGTCCCAAGA3'

TNF- $\alpha$; forward $5^{\prime}$-CTTCTCCTTCCTGATCGTGG-3', reverse $5^{\prime}$ GCTGGTTATCTCTCAGCTCCA3'

Nrf2; forward 5'-CCTCGCTGGAAAAAGAAGTG-3', reverse 5'-GGAGAGGATGCTGCTGAAAG-3

GAPDH; forward, 5'-TGCACCACCAACTGCTTAGC-3', reverse 5'GGCATGGACTGTGGTCATGAG3'

GAPDH was used as a housekeeping gene. Amplified products were separated using $1.5 \%$ agarose gel electrophoresis and visualized by UV trans-illuminator. The annealing temperature of IL-1 $\beta$, Nrf2, and GAPDH was $55^{\circ} \mathrm{C}, 60^{\circ} \mathrm{C}$ of IL- 6 , and $62{ }^{\circ} \mathrm{C}$ of TNF- $\alpha$. The expression level in the arbitrary unit was calculated $[27,50]$.

\subsection{Computational studies}

\subsubsection{Molecular docking study cholinesterases}

Molecular docking studies were conducted as per established protocols to predict the potential interactions of 2NCP with target sites of acetylcholinesterase and butyrylcholinesterase[39]. The 3D crystal structures of the protein complexes of cholinesteraseswere achieved from Protein Data Bank (PDB id 1ACl \& 1POI). The edited crystal structure was imported into MOE after the removal of water molecules. Hydrogen atoms were added to the structure followed by minimizing their energy using MOPAC 7.0. The model was subjected to a systematic conformational search at default parameters with the RMS gradient of $0.0001 \mathrm{kcal} / \mathrm{mol}$ using Site Finder. The active site of both enzymes was selected by the site finder tool of MOE. Root mean square deviation (RMSD) values were used to compare the ligand between the predicted and its corresponding crystal structure. The lowest energy minimized pose was used for further analysis. The 2NCP was docked following the same procedure. The resulting ligand-enzyme complex model was then used for binding interactions and binding pattern analysis.

\subsubsection{Molecular docking study withNF- $\kappa B$}

The most appropriate drug target for the compound was selected from the KEGG database (https://www.genome.jp/kegg). The pathway of Alzheimer's disease (HSA05010) showed that NF- $\mathrm{kB}$ regulates the production of TNF- $\alpha$, IL-1, and IL- 6 . Therefore compound was docked at the binding site of NF- $\mathrm{kB}$. The three-dimensional structure of NF- $\mathrm{kB}$ was taken from RCSB Protein Data Bank (https://www.rcsb.org/) with PDB ID: INFK [51]. The DNA binding residues were deduced and the compound was docked at the DNA binding site of NF-kB. Docking was performed on Molecular Operating Environment (MOE version 2009.14). The 3D-structure of the compound was built on MOE and MMFF-94x force field was applied to calculate the charges on the ligand. Similarly, hydrogen atoms and partial charges were applied to protein structures using the MMFF94 $\mathrm{x}$ force field. The $2 \mathrm{NCP}$ was docked within protein using the Triangle Matcher docking method and London dG scoring function of MOE. The best docked complex was selected on the basis of good interactions and docking score.

\subsection{Statistical analysis}

The in vitro (DPPH, AChE, BChE), ex vivo ( $A C h E, B C h E, G S T$, GSH, catalase, DPPH), and elevated plus maze, novel object recognition, spontaneous alternation behavior tests data were analyzed by Tukey's 
post hoc test. The light/dark box,balance beam,rotarod, time in the target quadrant and the target quadrant crossings (MWM), and RT-PCR tests datawere analyzed with one-way ANOVA followed by Dunnett post hoc test. The data of the time latency in the MWM and Y maze were analyzed by two-way ANOVA followed by Bonferroni test. The $\mathrm{IC}_{50}$ values were determined by nonlinear regression usingthe GraphPad Prism 5. Values were considered statistically different at $p<0.05$. The results were expressed as mean \pm S.E.M.

\section{Results}

\subsection{In vitro assays}

\subsubsection{Inhibition of cholinesterases by $2 N C P$}

The acetylcholinesterase (AChE) and butyrylcholinesterase (BChE) are enzymes of the brain cholinergic system responsible for the hydrolysis of the neurotransmitter acetylcholine. The brain levels of these enzymes show a progressive increase in $\mathrm{AD}$ [52]. The results of the in vitro assay of the 2NCP against AChE and BChEare shown in Table 1. The compound $2 \mathrm{NCP}$ has concentration dependant inhibitory properties against AChEand BChE. Inhibition of these enzymes was observed as 4 and $10 \%$ at a concentration of $7.8 \mu \mathrm{g} / \mathrm{ml}$, whereas it was 83 and $85 \%$ at a concentration of $1000 \mu \mathrm{g} / \mathrm{ml}$. The IC 50 values were determined against $A C h E$ and $B C h E$ which were 17 and $23 \mu \mathrm{g} / \mathrm{ml}$ respectively. Similarly, galanthamine exhibited $A C h E$ and $B C h E$ inhibition which was 11 and 16 $\%$ at $7.8 \mu \mathrm{g} / \mathrm{ml}$ concentration, whereas it was 89 and $91 \%$ at $1000 \mu \mathrm{g} / \mathrm{ml}$ with IC $_{50}$ values of 13 and $14 \mu \mathrm{g} / \mathrm{ml}$. Inhibition of $A C h E$ by the $2 \mathrm{NCP}$ was significant at a concentration of $31.25 \mu \mathrm{g} / \mathrm{ml}(* p<0.05)$. The $B C h E$ inhibited by the 2NCP significantly at concentration of 31.25 and 62.5 $\mu \mathrm{g} / \mathrm{ml}(p<0.05, p<0.001)$.

\subsubsection{DPPH radicals scavenging activity of $2 N C P$}

The free radicals and reactive oxygen species (ROS) play an important role in the development of oxidative stress that can lead to several diseases including AD.Antioxidants are exogenous or endogenous molecules that alleviate any form of oxidative stress [53].The antioxidant potential of the $2 \mathrm{NCP}$ was screened by the in vitro DPPH assay. This assay revealed concentration dependant anti-oxidant ability of the $2 \mathrm{NCP}$ ( $\mathrm{IC}_{50}$ $=62 \mu \mathrm{g} / \mathrm{ml}$ ) as shown in Table 2. Maximum inhibition was observed at

Table 1

Anti-cholinesterase activity of the 2-(hydroxy-(2-nitrophenyl)methyl)cyclopetanone(2NCP).

\begin{tabular}{|c|c|c|c|c|c|}
\hline \multirow[t]{3}{*}{ Samples } & \multirow[t]{3}{*}{$\begin{array}{l}\text { Conc. } \\
(\mu \mathrm{g} / \mathrm{ml})\end{array}$} & \multicolumn{2}{|c|}{$\begin{array}{l}\text { Acetylcholinesterase } \\
(A C h E)\end{array}$} & \multicolumn{2}{|c|}{$\begin{array}{l}\text { Buterylcholinesterase } \\
\text { (BChE) }\end{array}$} \\
\hline & & Inhibitions & $\mathrm{IC}_{50}$ & Inhibitions & $\mathrm{IC}_{50}$ \\
\hline & & (\%) & $\begin{array}{l}\mu \mathrm{g} / \\
\mathrm{ml}\end{array}$ & & $\begin{array}{l}\mu \mathrm{g} / \\
\mathrm{ml}\end{array}$ \\
\hline \multirow[t]{8}{*}{$2 \mathrm{NCP}$} & 07.8 & $4 \pm 2$ & 17 & $10 \pm 1$ & 23 \\
\hline & 15.6 & $27 \pm 6$ & & $22 \pm 3$ & \\
\hline & 31.25 & $44 \pm 3^{*}$ & & $46 \pm 4^{*}$ & \\
\hline & 62.5 & $55 \pm 2$ & & $53 \pm 2^{* *}$ & \\
\hline & 125 & $65 \pm 4$ & & $64 \pm 1$ & \\
\hline & 250 & $72 \pm 3$ & & $70 \pm 4$ & \\
\hline & 500 & $77 \pm 3$ & & $78 \pm 3$ & \\
\hline & 1000 & $83 \pm 3$ & & $85 \pm 4$ & \\
\hline \multirow[t]{8}{*}{ Galanthamine } & 07.8 & $11 \pm 2$ & 13 & $16 \pm 2$ & 14 \\
\hline & 15.6 & $36 \pm 2$ & & $32 \pm 6$ & \\
\hline & 31.25 & $54 \pm 3$ & & $57 \pm 2$ & \\
\hline & 62.5 & $62 \pm 2$ & & $70 \pm 5$ & \\
\hline & 125 & $71 \pm 2$ & & $75 \pm 3$ & \\
\hline & 250 & $77 \pm 3$ & & $80 \pm 4$ & \\
\hline & 500 & $85 \pm 2$ & & $88 \pm 3$ & \\
\hline & 1000 & $89 \pm 4$ & & $91 \pm 2$ & \\
\hline
\end{tabular}

Values shown in table are expressed as means \pm SEM. $p<0.05$ was considered significant statistically. ${ }^{*} p<0.05,{ }^{* *} p<0.01$, shows different significant values of the $2 \mathrm{NCP}$ as compared to the galanthamine treatment at the same concentration.
Table 2

Results of the 2-(hydroxy-(2-nitrophenyl)methyl)cyclopetanone (2NCP) in the in vitro DPPH radicals scavenging assay.

\begin{tabular}{lll}
\hline Samples & DPPH free radical scavenging \\
\hline \multirow{2}{*}{ 2NCP } & Concentration $(\mu \mathrm{g} / \mathrm{ml})$ & $\%$ Scavenging activity IC50 $\mu \mathrm{g} / \mathrm{ml}$ \\
& 07.8 & $7 \pm 1^{*} 62$ \\
& 15.6 & $13 \pm 2$ \\
& 31.25 & $27 \pm 3^{*}$ \\
& 62.5 & $45 \pm 4^{*}$ \\
& 125 & $57 \pm 2^{*}$ \\
& 250 & $70 \pm 4$ \\
Ascorbic acid & 500 & $80 \pm 2$ \\
& 1000 & $84 \pm 2$ \\
& 07.8 & $16 \pm 147$ \\
& 15.6 & $21 \pm 2$ \\
& 31.25 & $36 \pm 3$ \\
& 62.5 & $56 \pm 2$ \\
& 125 & $67 \pm 2$ \\
& 250 & $69 \pm 3$ \\
& 500 & $80 \pm 2$ \\
& 1000 & $89 \pm 2$ \\
\hline
\end{tabular}

Values shown in table are expressed as means \pm SEM. $P<0.05$ was considered significant statistically. ${ }^{*} p<0.05$ shows different significant values of the $2 \mathrm{NCP}$ as compared to the standard at same concentration.

the concentration of $1000 \mu \mathrm{g} / \mathrm{ml}$.

\subsection{In vivo assays}

\subsubsection{Effect of $2 N C P$ in the light/dark ( $L D)$ box test}

The light-dark (LD) box test is used to assess the unconditioned anxiety responses in rodents [54].The time latency of animal to enter into the dark compartment from the light compartment and the time spent in the light compartment were investigated in the LD box test. However, there was no obvious difference among all groups (Fig. 2. A\&B).

\subsubsection{Effect of $2 N C P$ in the balance beam test}

This test is used for the assessment of balance and motor coordination deficit in rodents. In the balance beam test the animals in all groups were crossed the beam successfully in same time, showed no defects in the balance of animals (Fig. 2.C).

\subsubsection{Effect of 2NCP in the rotarod test}

The transgenic 5xFAD and non-transgenic wild type (WT) mice fell from the rod at the same time, displayed no defects in the motorcoordination and balance of animals. Similarly, the $2 \mathrm{NCP}$ and galanthamine treated $5 x F A D$ mice showed the same latency time of falling (Fig. 2.D).

\subsubsection{Effect of the $2 N C P$ in the elevated plus maze (EPM) test}

The elevated plus maze (EPM) test is used to measure memory related behavior in rodents. The time in which the mice move from the open arm into the enclose arm is known as transfer latency (TL), which is used as an index of learning and memory in mice and rats[55].The effects of the 2NCP on learning, memory, and the response to a novel situation were assessed by observing their relative-exploration of two different environments. The transfer latencies in acquisition (day 1 ) and retention (day 2) trials were noted for all mice. The 5xFAD mice exhibited more transfer latency time in acquisition and retention trials as compared to the WT mice $(p<0.001)$. Whereas, the $5 \mathrm{xFAD}$ mice treated with the $2 \mathrm{NCP}(10 \mathrm{mg} / \mathrm{kg})$ transferred in less time from open into the close arm as compared to the 5xFAD mice $(p<0.05)$ in the retention trial. The mice treated with the $2 \mathrm{NCP}$ at the dose of $20 \mathrm{mg} / \mathrm{kg}$ exhibited a decrease in transfer latency in both trails as compared to the vehicle-treated 5xFAD mice ( $p<0.01, p<0.001$ ). The galanthamine $(\mathrm{GLN})$ and $2 \mathrm{NCP}(40 \mathrm{mg} / \mathrm{kg})$ showed a more significant reduction in transfer latency time in both trails $(p<0.001)$ (Fig. 3.A). 

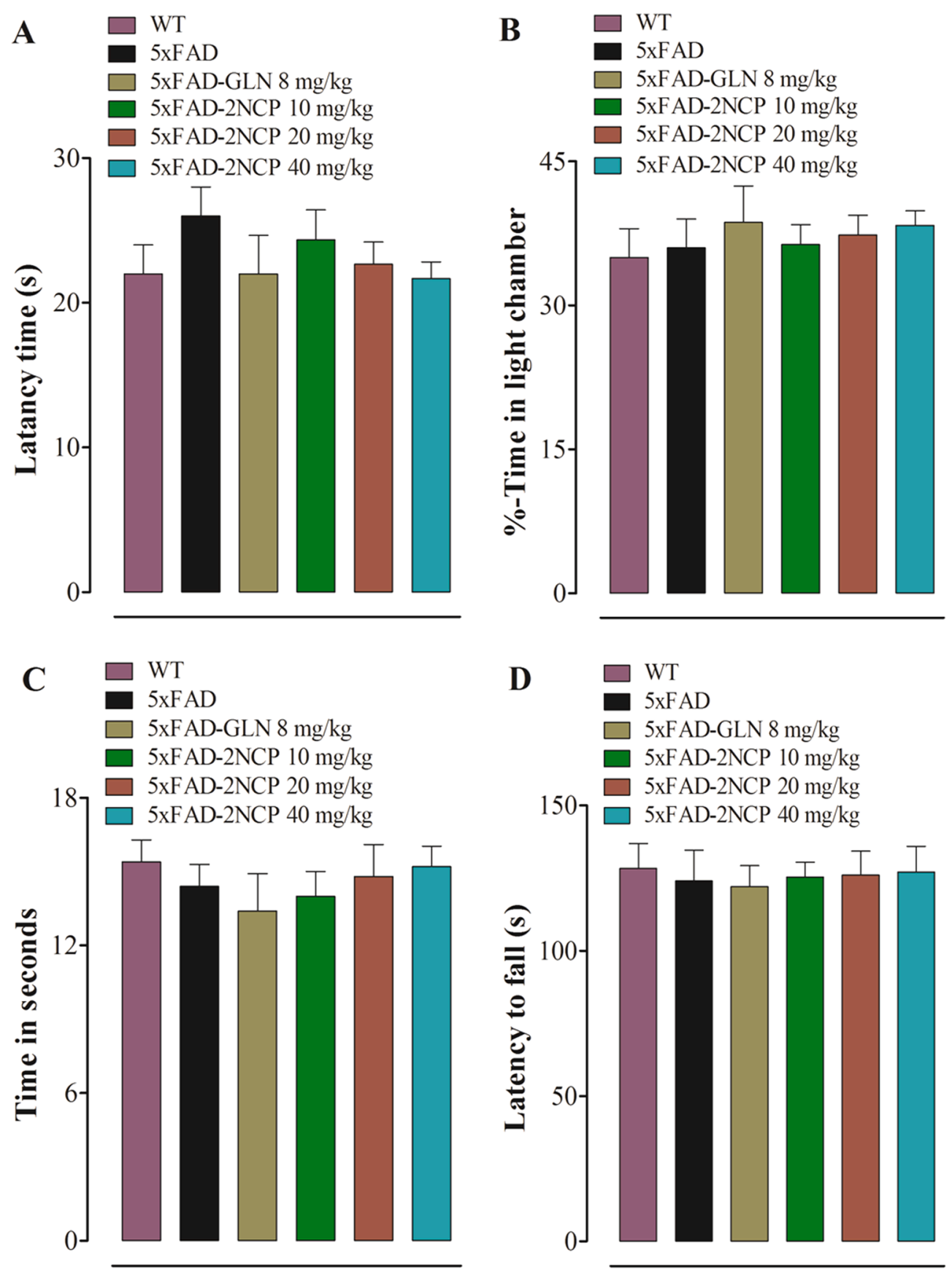

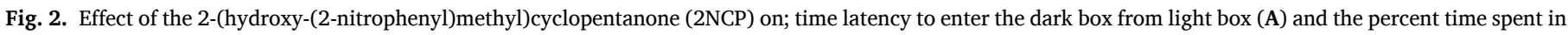

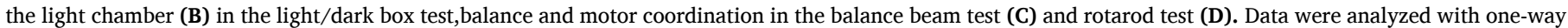
ANOVA followed by Dunnett post hoc test ( $\mathrm{n}=10$ mice/group).

\subsubsection{Effect of $2 N C P$ in the novel object recognition test}

Short and long term memory of mice was investigated by novel object recognition test. The $5 x F A D$ mice showed robust cognitive impairment as compared to the wild type mice, indicated by a significant decrease in the discrimination index $(\mathrm{p}<0.001)$. The $2 \mathrm{NCP}(10-40 \mathrm{mg} /$ $\mathrm{kg}$ ) treated mice displayed a significant recovery of cognitive function depicted by increased discrimination index in both memory tests (2-and 24-h) (p $<0.05, \mathrm{p}<0.01, \mathrm{p}<0.001$ ) (Fig. 3.B).

\subsubsection{Effect of 2NCP in the Y-Maze (Paddling) test}

Paddling Y-maze was performed for the analysis of spatial learning and memory [28].In the paddling Y-Maze test, escape latency time was determined for each group of animals for five consecutive days. The results showed that the $5 \mathrm{xFAD}$ group exhibited an increase in the latency time as compared to the WT-group $(p<0.001)$. The 2NCP at a low dose of $10 \mathrm{mg} / \mathrm{kg}$ showed a significant decrease in the latency time on days 4 and $5(p<0.05)$, at dose of $20 \mathrm{mg} / \mathrm{kg}$ caused significant decrease in the latency time on days 3,4 , and 5 ( $p<0.05, p<0.01, p<0.001$ ), while at high dose $(40 \mathrm{mg} / \mathrm{kg})$ caused a significant decrease in the time latency on days $2,3,4$, and $5(p<0.01, p<0.001)$, whereas the galanthamine $(8 \mathrm{mg} / \mathrm{kg})$ caused a significant decrease in the latency time on days 1 to 5 as compared to the $5 x$ FAD-group ( $p<0.05, p<0.01, p<0.001$ ). The 2NCP showed significant effects on the escape latencies [time $=(\mathrm{F}$ (4, $150)=17.9, p<0.0001)$, treatment $=(\mathrm{F}(5,150)=69, P<0.0001)$, interaction $=(\mathrm{F}(20,150)=1.05, p<0.4104)]$ and SAB $(\mathrm{F}(5,48)=$ 31.1, $p<0.0001$ (Fig. 3.C \& D). 


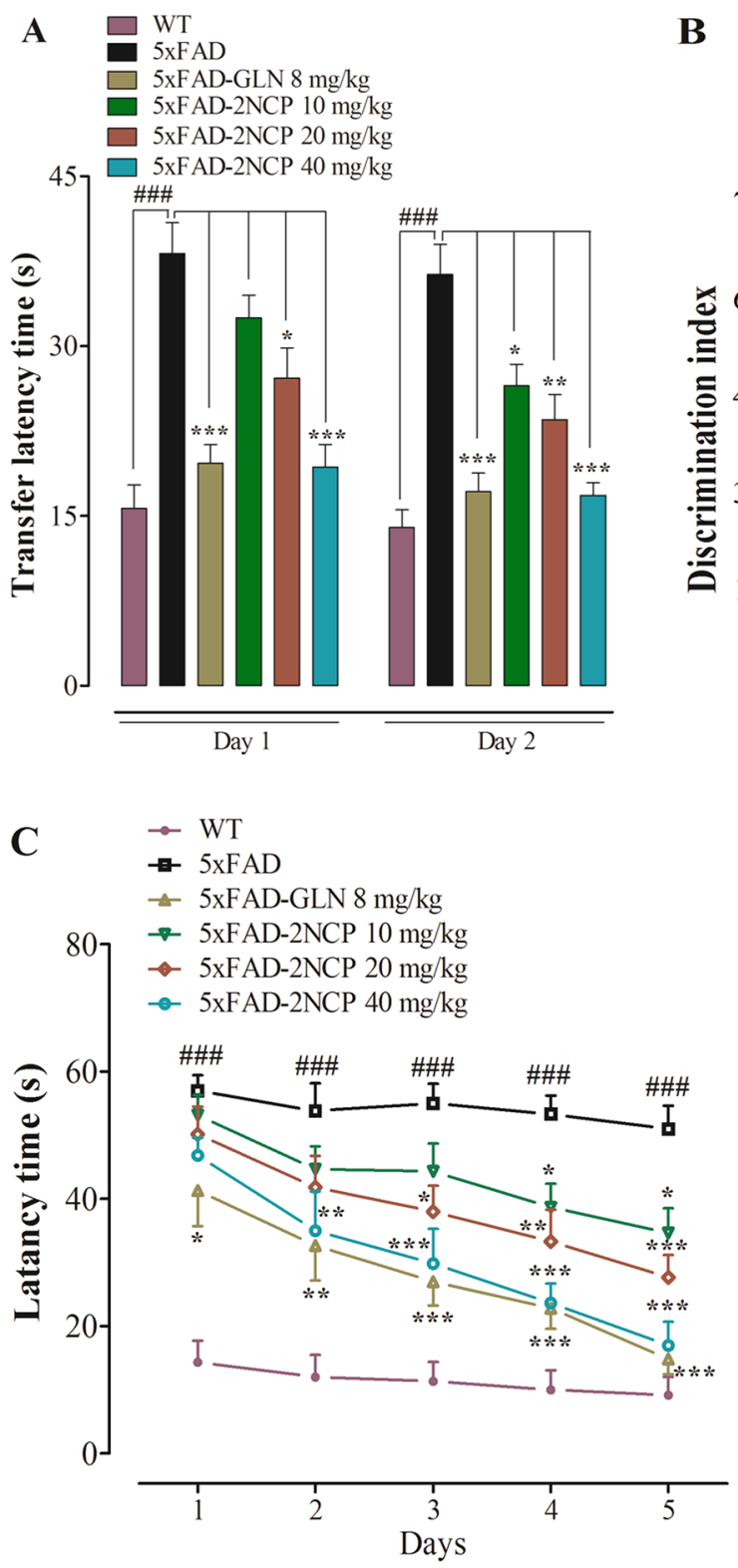

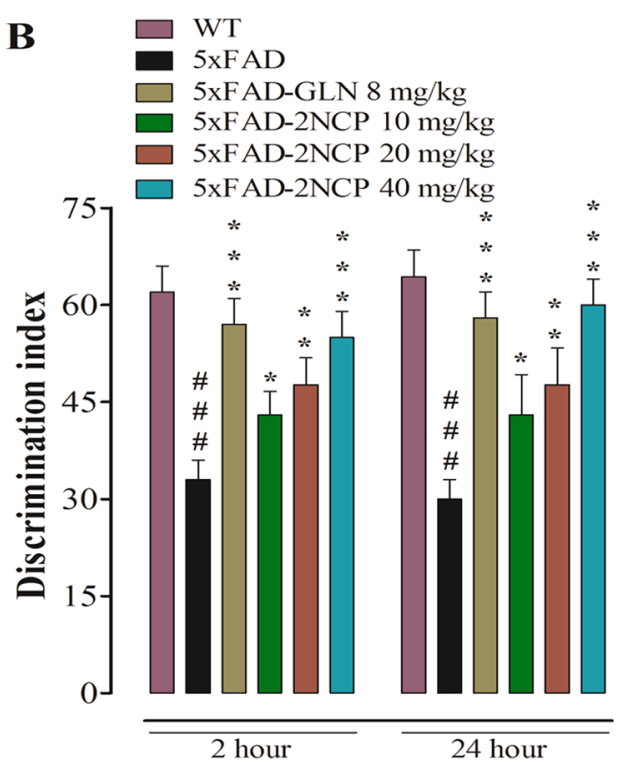

Fig. 3. The effect of 2-(hydroxy-(2-nitrophenyl)methyl)cyclopentanone (2NCP) on; memory in elevated plus maze (A),short- and long- term memory in novel object recognition test(B), spatial memory and SAB in the Y-Maze test (C \& D).The EPM, NOR, and SAB data were analyzed by one-way ANOVA followed by Tukey's post hoc test. The latency time data of Y-Maze were analyzed with twoway ANOVA followed by Bonferroni test. Bars represent mean \pm SEM. ${ }^{*} p<0.05,{ }^{*} p$ $<0.01, * * * p<0.001$ compared to the $5 x F A D$-group and ${ }^{\# \# \# p}<0.001$ compared to the WT group.
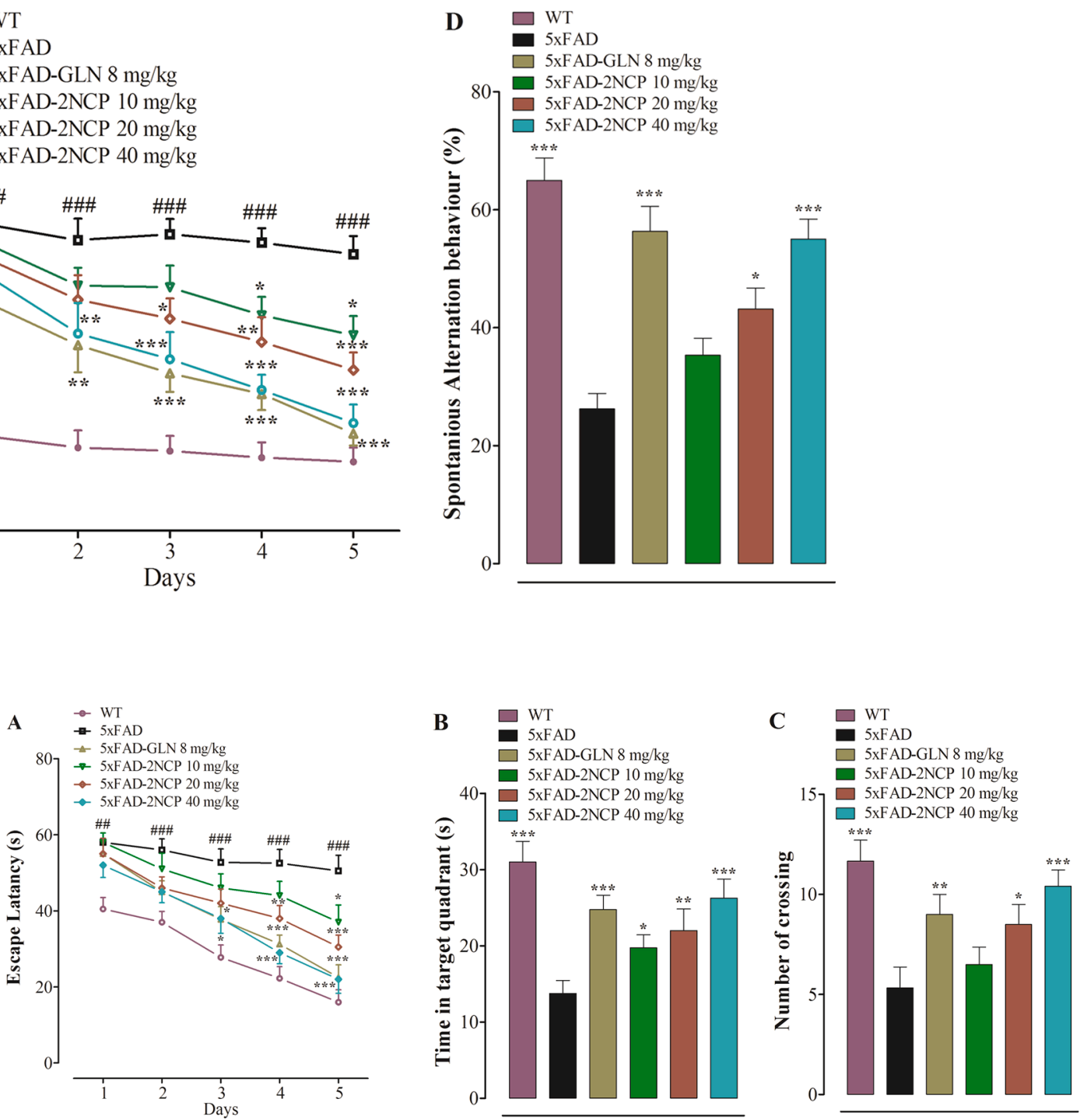

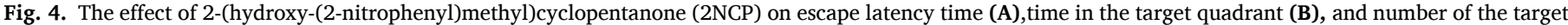

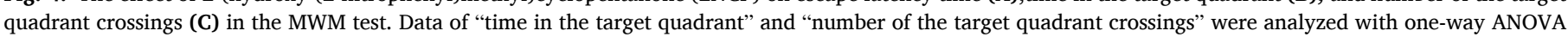

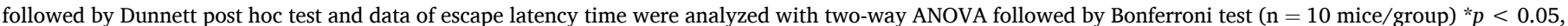
${ }^{* *} p<0.01,{ }^{* *} p<0.001$ compared to the 5xFAD-group and ${ }^{\# \# \#} p<0.001$ compared to the WT group. 


\subsubsection{Effect of $2 N C P$ in the Morris water maze (MWM) test}

Morris water maze test is commonly used for the evaluation of hippocampus dependant memory and learning in rodents [56].In the MWM test, the escape latency time was noted for each group of animals. The results revealed that the $5 \mathrm{xFAD}$ mice showed an increase in latency time as compared to the WT-mice $(p<0.001)$. The $2 \mathrm{NCP}$ at dose of $10 \mathrm{mg} / \mathrm{kg}$ shows a significant decrease in the latency time on the day $5(p<0.05)$, at a dose of $20 \mathrm{mg} / \mathrm{kg}$ exhibited a significant decrease in the latency on days 4 and $5(p<0.01, p<0.001)$, while the 2NCP at high dose $(40 \mathrm{mg} /$ $\mathrm{kg}$ ) and galanthamine $(8 \mathrm{mg} / \mathrm{kg})$ caused a significant decrease in the latency time on days 3,4 , and 5 as compared to the $5 x F A D$-group ( $p<$ $0.05, p<0.001$ ). Treatment with the $2 \mathrm{NCP}$ and galanthamine showed a significant effect on the escape latency [time $=(\mathrm{F}(4,90)=48.8, p<$ $0.0001)$, treatment $=(\mathrm{F}(5,90)=33.1, P<0.0001)$, interaction $=(\mathrm{F}(20$, $90)=1.15, p<0.3203)]$. In the probe trials, the 5xFAD mice treated with the vehicle spent less time in the target quadrant and exhibited less number of crossings over the platform place in the target quadrant, while the 2NCP-treated 5xFAD mice showed a reciprocal behavior to the 5xFAD mice treated with the vehicle $(p<0.05, p<0.01, p<0.001)$ (Fig. 4).

\subsection{Ex vivo assays}

\subsubsection{Effect of 2NCP on the cortical and hippocampal AChE, BChE} activities

The effects of the 2NCP and galanthamine on percent enzymatic activities of AChE in the hippocampus (HC) $(F(5,12)=20.8, p<$ $0.0001)$ and in the frontal cortex $(\mathrm{FC})(\mathrm{F}(5,12)=51.9, p<0.0001)$ is shown in Fig. 5A, while the significant changes produce by the galanthamine and 2NCP in the percent $B C h E$ activities in the hippocampus (HC) $(\mathrm{F}(5,12)=21.3, p<0.0001)$ and in frontal cortex $(\mathrm{FC})(\mathrm{F}(5,12)$ $=32, p<0.0001)$ of the brain is shown in Fig. $5 \mathbf{B}$. The 5xFAD mice exhibited a significant increase in the $A C h E$ and $B C h E$ activities in the HC and FC regions of the brain $(p<0.001)$. In both HC and FC, a significant decline in the $A C h E$ and BChEactivities has occurred with galanthamine and $2 \mathrm{NCP}$ treatment as compared to the $5 \mathrm{xFAD}$ animals ( $p<0.05, p<0.01, p<0.001)$. The 2NCP at doses of 10, 20, and 40 $\mathrm{mg} / \mathrm{kg}$ and galanthamine causes a significant reduction in the AChE and $B C h E$ activities in the HC and FC $(p<0.05, p<0.01, p<0.001)$.

\subsubsection{Effects of 2NCP the cortical and hippocampal GST, GSH, and} catalase activities

The brain levels of glutathione-S-transferase (GST), glutathione (GSH), and catalase decrease in oxidative stress associated with AD [57]. The activities and level of antioxidants;GST, GSH, and catalase reduced significantly in the HC and FC of the 5xFAD mice as compared to the WTmice. Treatment with the 2NCP enhances the percent activity of GST in the HC $(\mathrm{F}(5,12)=29.3, p<0.0001$ and FC $(\mathrm{F}(5,12)=20.1, p<$ 0.0001 . The $2 \mathrm{NCP}$ at doses of 10,20 , and $40 \mathrm{mg} / \mathrm{kg}$ showed an increase in the percent-activity of GST in both HC and FC ( $p<0.05, p<0.01, p$ $<0.001)$. The 2NCP treated groups showed an increase in GSH level in the $\operatorname{HC}(\mathrm{F}(5,12)=19.1, p<0.0001$ and FC $(\mathrm{F}(5,12)=13, p<0.0001$. The $2 \mathrm{NCP}$ at doses of 20 and $40 \mathrm{mg} / \mathrm{kg}$ showed an increase in GSH level (\%) in both HC and FC ( $p<0.01, p<0.001)$. The effect of 2NCP on percent catalase activity in the HC $(\mathrm{F}(5,12)=15.5, p<0.0001$ and FC $(\mathrm{F}(5,12)=100, p<0.0001$. The $2 \mathrm{NCP}$ at specified doses showed an increase in catalase activity (\%) in both $\mathrm{HC}$ and FC $(p<0.05, p<0.01$, $p<0.001$ ) (Fig. 5.C, D, E).

\subsubsection{Effect of 2NCP the cortical and hippocampal DPPH scavenging activity}

The level of antioxidant proteins in the HC $(F(5,12)=29.8, p<$ $0.0001)$ and $\mathrm{FC}(\mathrm{F}(5,12)=25.2, p<0.0001)$ is shown in Fig. 5.F. Homogenates from the brain of the 5xFAD mice showed a significant decrease in the percent scavenging activity in the HC and FC as compared to the WT-mice $(p<0.001$ ), while the galanthamine and 2NCP treated animals exhibited a significant increase in percent scavenging activity in both areas (Fig. 5.F).
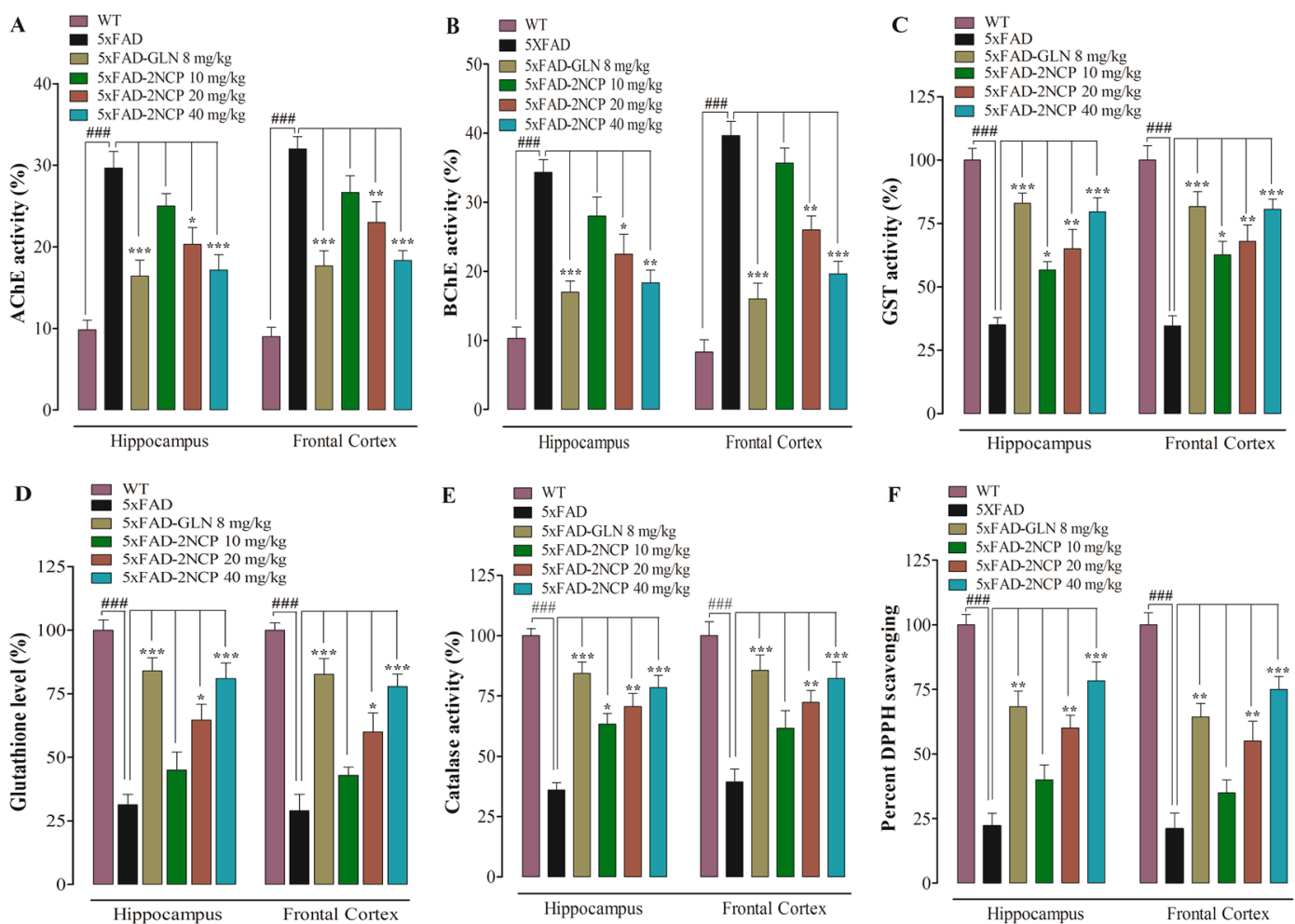

Fig. 5. Effect of the 2-(hydroxy-(2-nitrophenyl)methyl)cyclopentanone (2NCP) on the level/activity of $A C h E(A), B C h E(B), G S T$ (C), GSH (D), catalase (E), and DPPH percent scavenging activities of proteins (F)in the HC and FC. Through one way ANOVA followed by Tukey's post hoc test data were analyzed. Bars represent mean

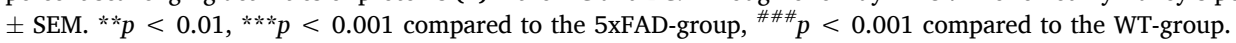




\subsection{RT-PCR studies}

3.4.1. Effect of $2 N C P$ pro-inflammatory cytokines ( $I L-1 \beta, I L-6, T N F-\alpha$ ) in the $H C$ and $F C$

Inflammation has been involved in $\mathrm{AD}$ pathogenesis. The interleukin-1 $\beta$ (IL-1 $\beta$ ), interleukin-6 (IL-6), and tumor necrosis factor (TNF- $\alpha$ ) are vital pro-inflammatory factors, play an important role in the chronic neuroinflammatory processes in $\mathrm{AD}$, and high levels of these cytokines may be strong indicators for the AD progression [58].To find out the neuro anti-inflammatory effects of the $2 \mathrm{NCP}$, the expression of various cytokines was evaluated using RT-PCR. The 5xFAD mice exhibited an increased mRNA level of IL- $1 \beta$, IL- 6 , and TNF- $\alpha$ as compared to the WT mice. After the treatment of the $2 \mathrm{NCP}$ and galanthamine, the mRNA level of these cytokines was significantly reduced as compared to the $5 \times$ FAD group $(p<0.01, p<0.001)$ (Fig. 6).
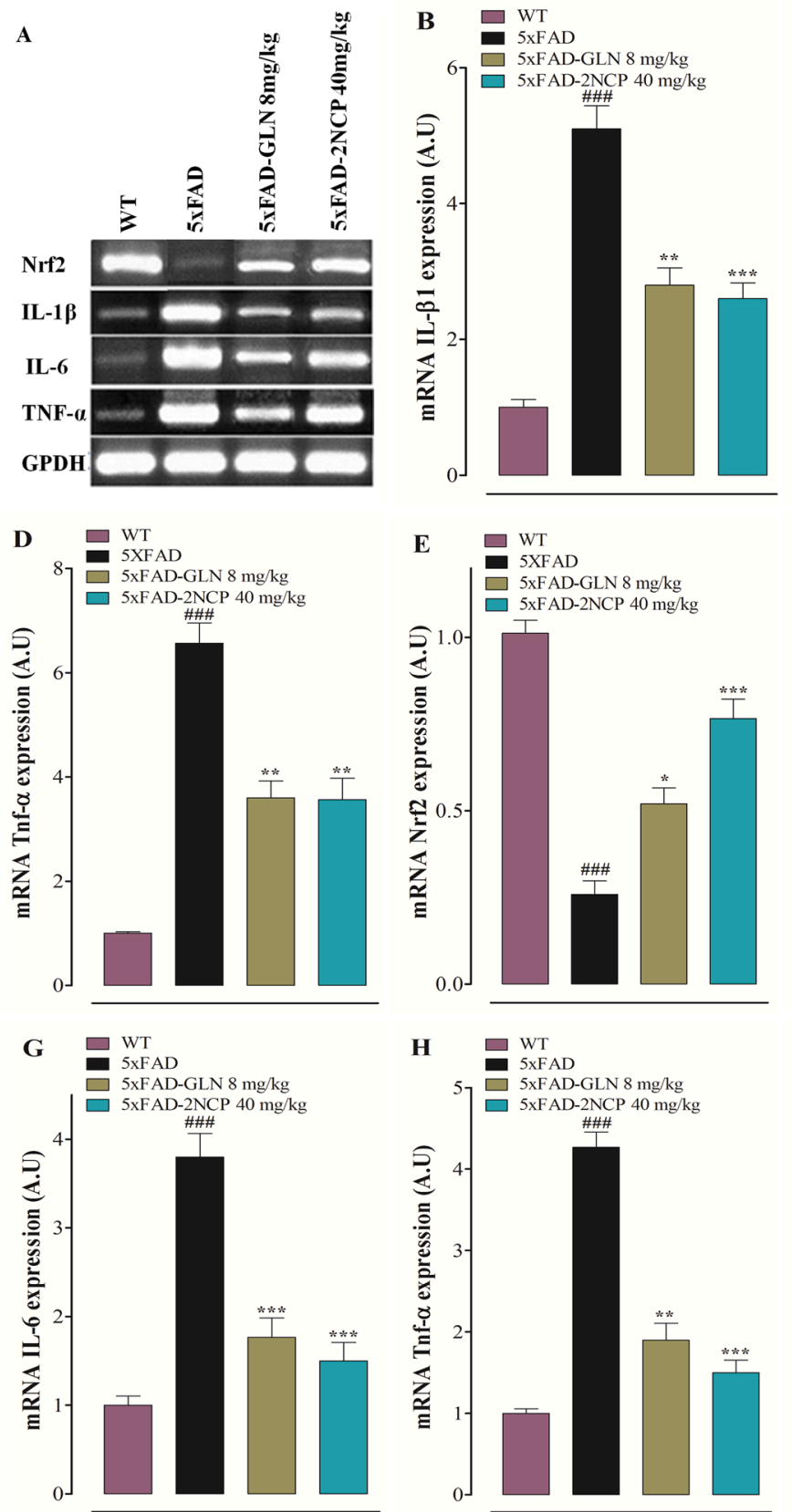

3.4.2. Effect of $2 N C P$ on anti-oxidant response elements in the HC and FC Activation of nuclear factor erythroid 2-related factor (Nrf2) protects human bodies from deleterious stress by up-regulating anti-oxidative defense-pathway and inhibiting inflammation. It is reported that Nrf2activators have therapeutic potential in AD-animal models [59]. The level of Nrf2 reduced in the hippocampus and frontal cortex of the $5 \mathrm{xFAD}$ mice, while the $5 \mathrm{xFAD}$ mice treated with the 2NCP significantly enhance the mRNA level of Nrf2 $(p<0.001)$ (Fig. 6.E \& I)

\subsection{Computational studies}

\subsubsection{Computational study with cholinesterases}

The molecular study was performed to rationalize the binding mechanism of 2NCP with cholinesterases. Many studies have described the role of acetylcholinesterase $(A C h E)$ and butyrylcholinesterase $(B C h E)$ in the underlying mechanism of $\mathrm{AD}$ [60]. Therefore $A C h E$ and $B C h E$ were selected as biological targets for the docking of

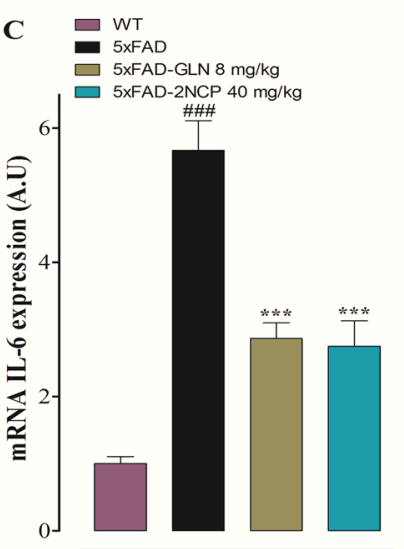

Fig. 6. The effect of 2-(hydroxy-(2-nitrophenyl)methyl)cyclopentanone (2NCP) on mRNA expression of IL-1 $\beta$, IL- 6 , TNF- $\alpha$, and Nrf2 was confirmed by RT-PCR (A).The effects of the $2 \mathrm{NCP}$ on the mRNA level of IL- $1 \beta$ (B\&F), IL-6 (C\&G), TNF- $\alpha(\mathbf{D} \& \mathbf{H})$, and Nrf2 $(\mathbf{E} \& \mathrm{I})$ in the $\mathrm{HC}$ and $\mathrm{FC}$ of transgenic mice. The results are shown in relative arbitrary unit (A.U). Each group containing four animals and bars represent mean expression in A.U \pm SEM. The datawere analyzed with one-way ANOVA followed by Dunnett post hoc test. ${ }^{* *} p<0.01,{ }^{*} * * p<0.001$ compared to the 5xFAD-group and ${ }^{\# \# \# ~}<0.001$ compared to the WT-group.
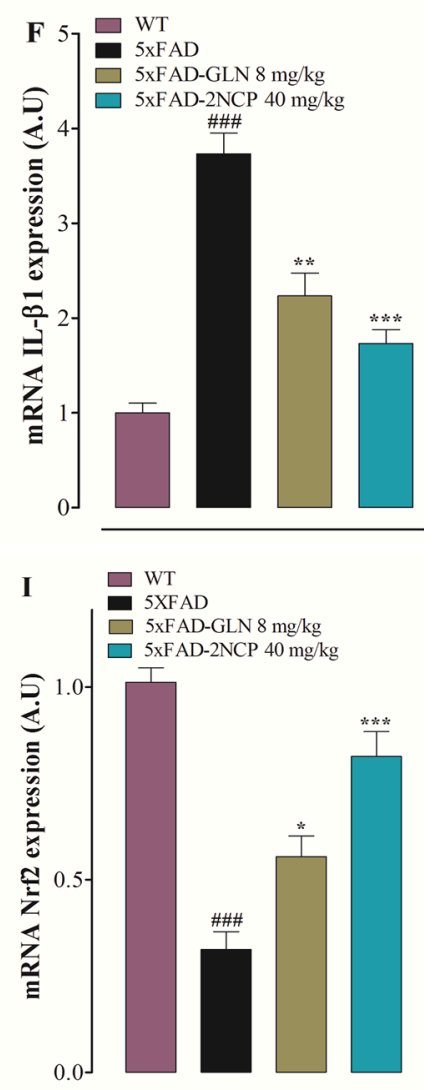
2NCP. When the 2NCP docked at the binding site of AChE, and the Glu199 groups of 2NCP mediated hydrogen bonds with the Tyr 130 of AChE. The bond length was $2.4 \AA$ and the bond-energy $-9.42 \mathrm{Kcal} / \mathrm{mol}$.

The docked orientation of the $2 \mathrm{NCP}$ at the BChE binding site revealed that inhibitor binds nicely within the binding groove and the -OH group of the $2 \mathrm{NCP}$ formed strong hydrogen bond with the $B C h E$ through Arg 242 at a distance of $2.88 \AA$. The docking score of the $2 \mathrm{NCP}$ was highly negative $(-10.51)$ at the ligand binding site of BChE. The findings of the docking study show that the AChEandBChEcould be potential targets for the 2NCP. The docked orientation of the $2 \mathrm{NCP}$ is presented in the Fig. 7.

\subsubsection{Computational study withNF- $\kappa B$}

Using the KEGG pathway,it was deduced that NF- $\mathrm{KB}$ regulates the production and expression of different cytokines including TNF, IL-1, IL6 , iNOS, COX2, and M-CSF. Since the 2NCP reduced the mRNA levels of the inflammatory mediators (IL-1 $\beta$, IL- 6 , TNF- $\alpha$ ), therefore, it may bind with NF- $\kappa B$ to exhibit its activity. The binding of the 2NCP with NF$\kappa B$ as confirmed by molecular docking studies. The homodimer of NF$\kappa \mathrm{B}$ (p50 subunit) binds with DNA, where several residues including Arg54, Arg56, Tyr57, Cys59, Glu60, Lys144, Gln274 and Gln306 of Chain A, and Arg54, Glu60, Pro62, Lys144, Gln274, Arg305 and Gln306 of Chain B are involved in protein-DNA complex formation. The binding residues are shown in Fig. 8.A. The compound 2NCP was targeted at both chains. The 2NCP showed excellent binding interactions at the binding hotspot of Chain $\mathrm{B}$, where the compound was stabilized by the hydrogen bonding with the side chains of Thr143 and Lys145. The $-\mathrm{OH}$ group of the 2NCP donated H-bond to the side chain of Thr143 at a distance of $2.04 \AA$, while the nitro group of the 2NCP accepted H-bond from the side chain of Lys145 with the bond length of $2.21 \AA$. The docking score of the $2 \mathrm{NCP}$ was $-5.51 \mathrm{Kcal} / \mathrm{mol}$. The good binding interactions and high docking score suggest that the $2 \mathrm{NCP}$ has a binding potential with NF- $\mathrm{kB}$. The binding mode of the 2NCP is shown in Fig. 8 . B.

\section{Discussion}

Chronic neuroinflammation and oxidative stress serve a key role in Alzheimer's disease (AD). According to the cholinergic hypothesis, memory impairment in $\mathrm{AD}$ patients also linked with the deficit in cholinergic function of the brain. Although there are five drugs approved by the FDA for the treatment of $\mathrm{AD}$, these drugs provide symptomatic relief to patients not cure the cause of $\mathrm{AD}$ [61-62]. Evidence suggests that neuroinflammation suppression is considered a fascinating therapeutic entity to halt the development of $\mathrm{AD}$ [63].

Decrease level of acetylcholine (ACh) is responsible for cognitive impairment in AD. Acetylcholinesterase (AChE) hydrolyzes ACh thus terminate the cholinergic-transmission. Therefore, AChE inhibition is supposed to compensate for the reduced ACh level in the brain [64]. In this study, the anti-cholinesterase potential of the 2NCP was assessed in the in vitro and ex vivo studies. The $2 \mathrm{NCP}$ produced beneficial effects similar in intensity to that produced by standard, galanthamine. Galanthamine inhibits the acetylcholinesterase enzyme reversibly and competitively, effective for the symptomatic treatment of AD [65]. The in vitro anti-cholinesterase assay revealed that the $2 \mathrm{NCP}$ has concentration dependant $A C h E$ and $B C h E$ inhibition properties. The $\mathrm{IC}_{50}$ values were determined against $A C h E$ and $B C h E$ enzymes which were 17 and $23 \mu \mathrm{g} / \mathrm{ml}$ respectively. The $2 \mathrm{NCP}$ caused significant inhibition of percent activities of $A C h E$ and $B C h E$ in the HC and FC tissues of the 5xFAD mice. Therefore due to the inhibition of the AChE and BChE, the level of
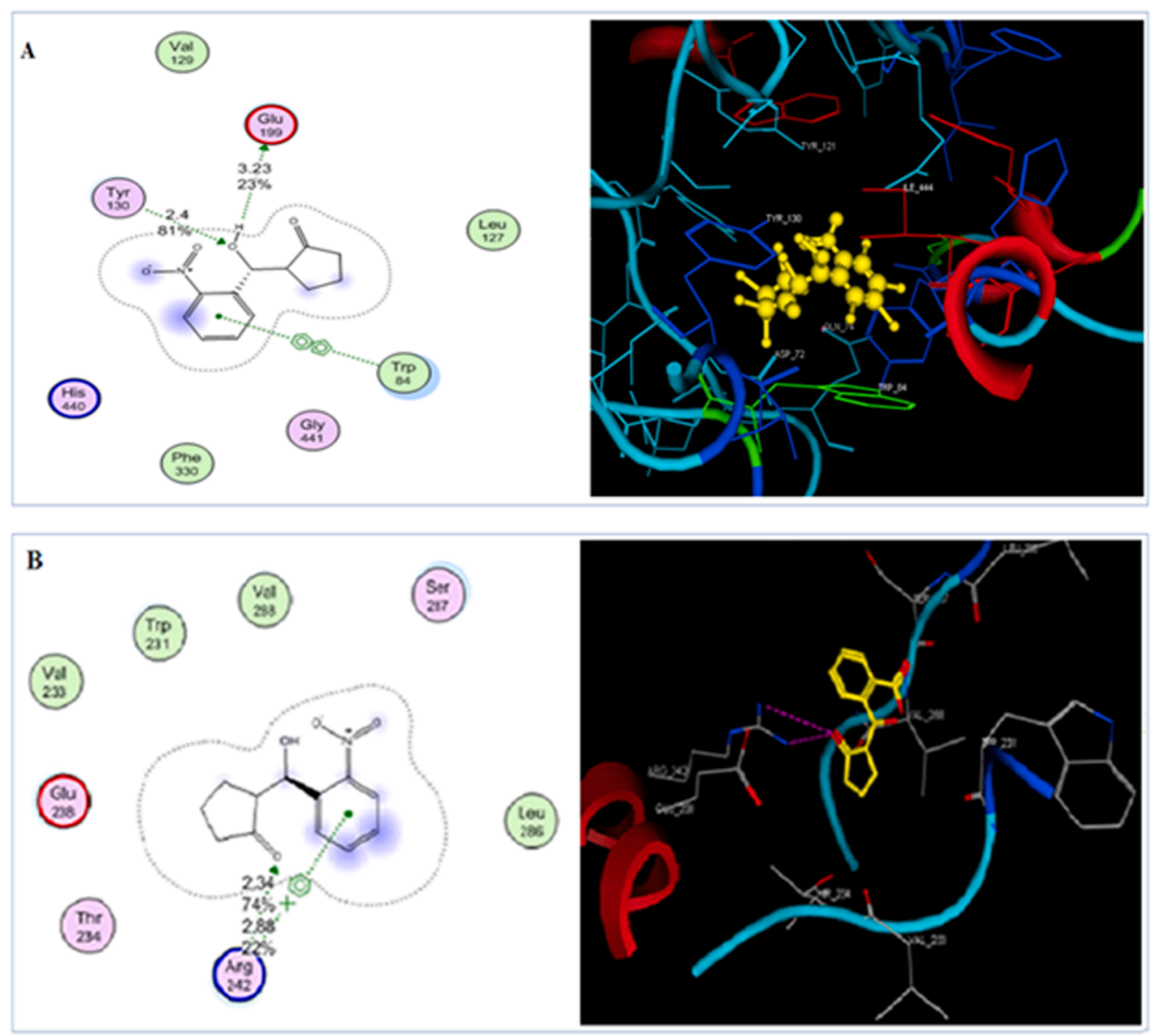

Fig. 7. 2D and 3D docked view of $2 \mathrm{NCP}$ in a pocket of $A C h E$ (A) and BChE enzymes (B). 
A
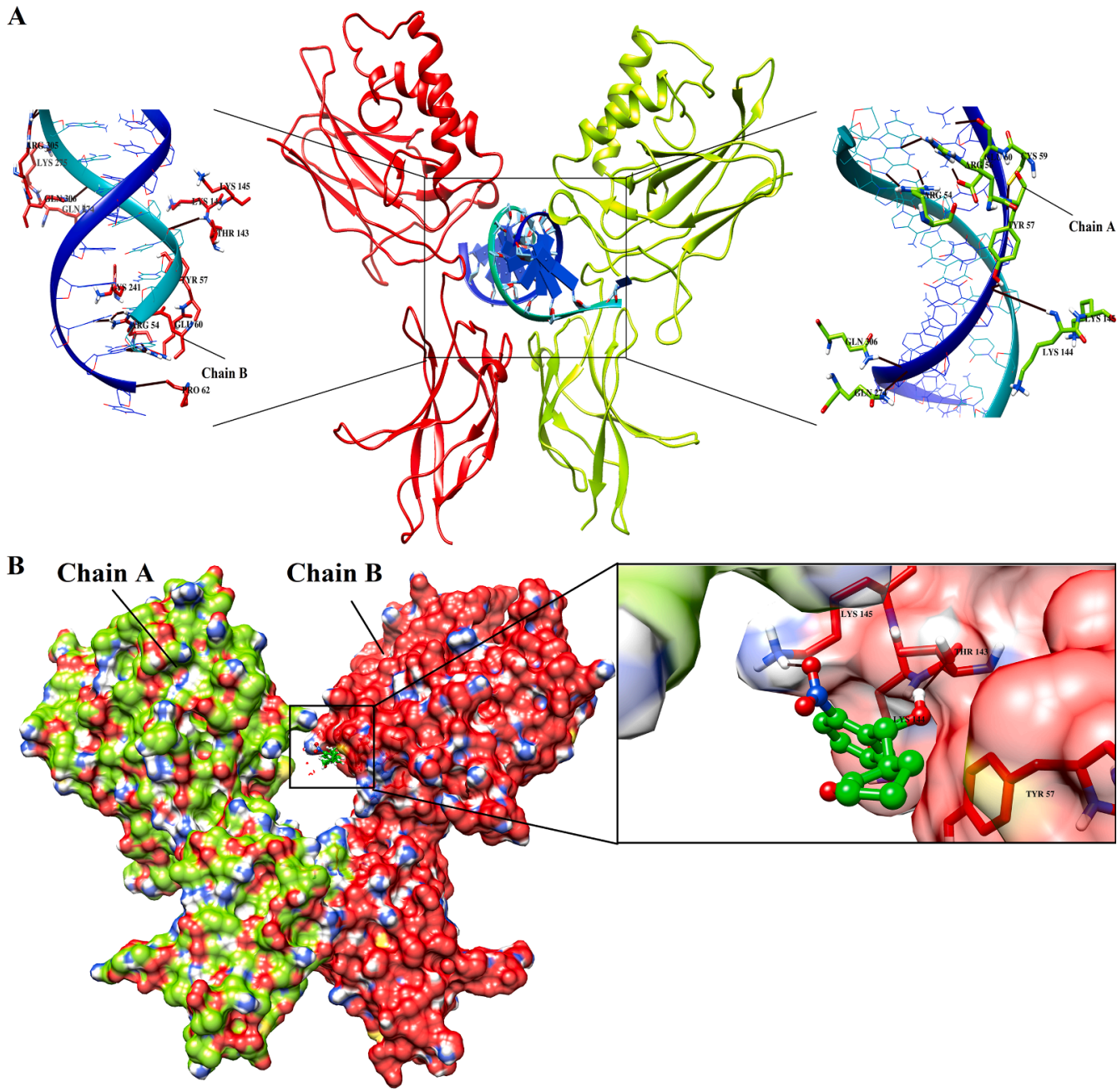

Fig. 8. (A) The 3D-structure of homodimer NF- $\kappa$ B in complex with dsDNA is shown. The chain A and B of homodimer are presented in green and red ribbons. The double strands of DNA are shown in the blue and cyan ribbon models. The binding residues of chains $\mathrm{A}$ and $\mathrm{B}$ are also highlighted in green and red stick models in their respective chains. The hydrogen bonds between DNA and the

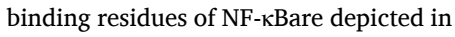
black lines.(B) The binding mode of the 2-(hydroxy-(2-nitrophenyl)methyl) cyclopetanone (2NCP) in the binding cavity of chain B of NF- $\kappa \mathrm{B}$ is shown in figure. The protein-ligand interactions are highlighted in the box. The ligand (2NCP) is presented in the green ball and stick model, while binding residues are shown in the red stick model, while $\mathrm{H}$-bonds are shown in black lines. acetylcholine in the synaptic cleft maintained for a long time, which stimulates cholinergic receptors. The augmented cholinergic conduction by the $2 \mathrm{NCP}$ shows their usefulness in memory restoration in AD.

Oxidative stress plays an important role in the pathogenesis of AD. It has been reported that the increased level of $A \beta 1-40$ and $A \beta 1-42$ is associated with an elevated level of oxidative stress products generated from different organic substances in the cortex and hippocampus of AD individual, while brain regions such as the cerebellum having a low level of $A \beta$ due to fewer concentrations of oxidative stress markers $[7,66]$. Antioxidants such as catalase, glutathione (GSH), and glutathione-Stransferase (GST) play an important role in preventing or reducing the progression of oxidative stress-mediated by free radicals [67-69]. GSH level, GST and catalase activities decreased in AD and mild cognitive impairment as compared to the normal brain [70-72]. Nrf2 plays a key role in the cellular redox system regulation; protects many CNS cell types from ROS. Susceptibility to oxidative stress increased by decreasing Nrf2 levels. Expression of Nrf2 in the AD brain decreases significantly as compared to the normal brain and their activity reduced in the hippocampal and frontal cortex neurons, over expression of the Nrf2 in the HC and FC improves spatial learning and memory [73]. Molecule with the active antioxidant potential is used to scavenge such harmful radicals [19]. The 2NCP has promising antioxidant potential, since it scavenged DPPH free radicals, considerably improved the activities of GST and catalase, and enhanced the level of GSH and Nrf2 in the $\mathrm{HC}$ and $\mathrm{FC}$ of transgenic 5xFAD mice.

Neuroinflammation has a vital role in causing cognitive impairment and neurodegenerative disorders, it occurs around the $\mathrm{A} \beta$ plaques, characterized by elevated levels of free radicals, pro-inflammatory cytokines, and activation of astro- and microglia [74-75]. Proinflammatory cytokines such as IL- $1 \beta$, IL- 6 , and TNF- $\alpha$ are upregulated in the brain of $\mathrm{AD}$ patients and transgenic $5 \times \mathrm{XFD}$ mice [76-81]. In RT-PCR study it is shown that the 2NCP reduced the level of these pro-inflammatory cytokines in the $\mathrm{HC}$ and $\mathrm{FC}$ of the transgenic mice, specifically the $2 \mathrm{NCP}$ caused more reduction in the TNF- $\alpha$ level than galanthamine.

$\mathrm{NF}-\mathrm{kB}$ signaling plays an important role in gene regulation and is implicated in inflammation, oxidative stress, and apoptosis. The level of $\mathrm{NF}-\kappa \mathrm{Bis}$ significantly increased in the brain of $\mathrm{AD}$ patients. The elevated

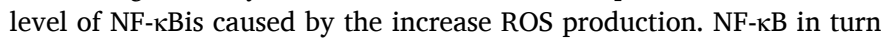
increases the expression of several cytokines including iNOS, COX2, TNF- $\alpha$, IL-1, IL-6, and M-CSF. These cytokines subsequently reduce the long-term potentiating in $\mathrm{AD}$ patients [82]. Thus, the compound $2 \mathrm{NCP}$ was docked at the binding cavities of NF- $\mathrm{KB}$ which revealed that the $2 \mathrm{NCP}$ is well accommodated in the DNA binding site of NF- $\mathrm{kB}$ with high binding energy. The docking scores and binding interactions suggest that the 2 NCP reduces the level of TNF- $\alpha$, IL- $1 \beta$, and IL- 6 by targeting the NF-kB.

The light/dark box, balance beam, rotarod, EPM, NOR, paddling Ymaze, and MWM tests were performed for determining the effect of the $2 \mathrm{NCP}$ on the behavior of the $5 \mathrm{xFAD}$ mice in terms of anxiety, balance, motor coordination, hippocampal-dependent spatial learning and memory, respectively [27-28].

The light/dark box test was performed for the assessment of anxiety. The time latency to enter the dark compartment and the time spent in 
the light compartment were noted in this test. No significant differences were observed among all groups, indicates that the 2NCP did not cause anxiety.

The balance beam and rotarod assays have been an effective tool in measuring balance and motor coordination [83]. The number of variables can be recorded from the balance beam and rotarodtests for the assessment of balance (time spent on balance beam instrument) and coordination (latency time to fall from the rod). Mice were tested on the balance beam and rotarod, the results showed no significant difference in time duration on the balance beam and latency times of falling among all groups of animals implying that the 2NCP did not cause any balance and motor deficits.

Elevated plus maze (EPM) test is used for the assessment of anxiety, spatial learning and memory in mice [84-85]. Reduce latency time (TL) in the EPM task indicated the improvement in memory and learning, while increase TL indicates memory impairment [86]. The results of the EPM test showed that the 2NCP decreased the TL in the retention phase indicate improved memory.

The novel object recognition (NOR) test was used for the assessment of short- and long term memory [87]. The 5xFAD mice treated with vehicle exhibited cognitive deficits indicated by decreased discrimination index, while the $2 \mathrm{NCP}$ reversed the cognitive deficits presented by the transgenic 5xFAD mice in the NOR test paradigm.

In the paddling Y-Maze test, the escape latency time was recorded for five days consecutively. The $5 x \mathrm{xAD}$ mice treated with the vehicle displayed low memory indicated by high escape latency times. The 2NCP $(40 \mathrm{mg} / \mathrm{kg}$ ) exhibited a significant improvement in memory on days 2,3 , 4 , and 5 in comparison with other groups, while the $2 \mathrm{NCP}$ at the dose of $20 \mathrm{mg} / \mathrm{kg}$ has a significant effect on memory on days 3,4 , and 5 . The $5 x F A D$ mice treated with the $2 \mathrm{NCP}(10 \mathrm{mg} / \mathrm{kg})$ exhibited a decrease in the escape latency on days 4 and 5 . Spontaneous alternation behavior (SAB) of the animals was observed on day 5 and expressed as percent activity. A high level of SAB shows less memory impairment and better cognitive function, while the decrease level of $\mathrm{SAB}$ indicates less working memory [88].

The Morris water maze (MWM) task is used for the assessment of spatial learning and memory in rodents; also it can be used to investigate the damage to particular cortical regions of the brain [89]. In the MWM task, during training trials spatial information acquisition was assessed, while in probe trials memory retention was determined. The $5 \mathrm{xFAD}$ mice exhibited memory impairment and require more time to find the platform as compared to the WT-mice in training trials. While in the probe trial, these transgenic mice exhibited a significant decline in the time spent in the target quadrant and number of crossings over target quadrant. The $5 \mathrm{xFAD}$ mice treated with the $2 \mathrm{NCP}$ displayed a significant decrease in the latency time during training trials, more time in the target quadrant and frequent crossing over the target quadrant during probe trials as compared to the $5 \mathrm{xFAD}$ mice treated with the vehicle.

\section{Conclusion}

In conclusion, the current study revealed that the $2 \mathrm{NCP}$ has significant antioxidant, anticholinesterases, anti-neuroinflammatory and attenuative potential against memory impaiment in the $5 \mathrm{xFAD}$ transgenic mice. The beneficial effects of $2 \mathrm{NCP}$ appear to occur through various mechanisms; including the scavenging of the DPPH free radicals, inhibition of the AChE, BChE, and NF- $\mathrm{KB}$, inhibition of induction of cytokines (IL-1 $\beta$, IL-6, TNF- $\alpha$ ) and Nrf2. 2NCP is useful because of lack of motor coordination deficit. Hence, our findings suggest that the 2NCP might be a multi-targeted drug for the treatment of $\mathrm{AD}$. However, more comprehensive studies are required to explore the detailed mechanistic role of the $2 \mathrm{NCP}$ against the Alzheimer's disease.

\section{CRediT authorship contribution statement}

Rahim Ullah: Writing- original draft, Conceptualization,
Methodology, Software. Gowhar Ali: Supervision, Writing - review \& editing. Fazal Subhan: Supervision, Investigation. Ajmal Khan: Methodology, Validation. Sobia Ahsan Halim: Methodology, Software. Muhammad Naveed: Data curation, Software. Saima Kalsoom: Methodology, Software. Ahmed Al-Harrasi: Data curation, Validation.

\section{Declaration of Competing Interest}

The authors declare that they have no known competing financial interests or personal relationships that could have appeared to influence the work reported in this paper.

\section{Acknowledgments}

We are gratified to Higher Education Commission (HEC) of Pakistan for budgetary sustenance as this study is part of the project has been awarded by the HEC under the National Research Programme for Universities (NRPU), No: 6671/KP/NRPU/R\&D/HEC/2016. The 2NCP has been synthesized as a part of series of compounds and confirmed their structures by Dr. Muhammad Naveed Umar, Associate Professor, Department of Chemistry, and University of Malakand, Pakistan. We are grateful to him for providing a series of compounds and after preliminary studies; we selected the cited compound for our study.

\section{References}

[1] M.L. Calió, A.C. Mosini, D.S. Marinho, G.N. Salles, F.H. Massinhani, G.M. Ko, M. A. Porcionatto, Leptin enhances adult neurogenesis and reduces pathological features in a transgenic mouse model of Alzheimer's disease, Neurobiology of disease 148 (2021), 105219.

[2] L.E. Rojo, J.A. Fernández, A.A. Maccioni, J.M. Jimenez, R.B. Maccioni, Neuroinflammation: implications for the pathogenesis and molecular diagnosis of Alzheimer's disease, Archives of medical research39(1) (2008) 1-16.

[3] A. Kumar, A. Singh, A review on Alzheimer's disease pathophysiology and its management: an update, Pharmacol. Rep. 67 (2) (2015) 195-203.

[4] I.O. Ishola, M.O. Osele, M.C. Chijioke, O.O. Adeyemi, Isorhamnetin enhanced cortico-hippocampal learning and memory capability in mice with scopolamineinduced amnesia: role of antioxidant defense, cholinergic and BDNF signaling, Brain Res. 1712 (2019) 188-196.

[5] G.V. De Ferrari, M.A. Canales, I. Shin, L.M. Weiner, I. Silman, N.C. Inestrosa, A structural motif of acetylcholinesterase that promotes amyloid $\beta$-peptide fibril formation, Biochemistry 40 (35) (2001) 10447-10457.

[6] S.K. Singh, A. Patra, Evaluation of phenolic composition, antioxidant, antiinflammatory and anticancer activities of Polygonatum verticillatum (L.), Journal of integrative medicine 16 (4) (2018) 273-282.

[7] C. Cheignon, M. Tomas, D. Bonnefont-Rousselot, P. Faller, C. Hureau, F. Collin, Oxidative stress and the amyloid beta peptide in Alzheimer's disease, Redox Biol. 14 (2018) 450-464.

[8] S.K. Das, D. Vasudevan, Alcohol-induced oxidative stress, Life Sci. 81 (3) (2007) $177-187$.

[9] M.R. Saha, P. Dey, S. Begum, B. De, T.K. Chaudhuri, D.D. Sarker, A.P. Das, A. Sen, Effect of Acacia catechu (Lf) Willd. on oxidative stress with possible implications in alleviating selected cognitive disorders, PLoS ONE 11 (3) (2016), e0150574.

[10] P. Scartezzini, E. Speroni, Review on some plants of Indian traditional medicine with antioxidant activity, J. Ethnopharmacol. 71 (1-2) (2000) 23-43.

[11] A.V. Meszaros, A. Weidinger, G. Dorighello, M. Boros, H. Redl, A.V. Kozlov, The Impact of Inflammatory Cytokines on Liver Damage Caused by Elevated Generation of Mitochondrial Reactive Oxygen Species, Free Radical Biol. Med. 100 (2016) S57.

[12] A. Diplock, J.-L. Charuleux, G. Crozier-Willi, F. Kok, C. Rice-Evans, M. Roberfroid, W. Stahl, J. Vina-Ribes, Functional food science and defence against reactive oxidative species, Br. J. Nutr. 80 (S1) (1998) S77-S112.

[13] S.O. Onoja, Y.N. Omeh, M.I. Ezeja, M.N. Chukwu, Evaluation of the in vitro and in vivo antioxidant potentials of Aframomum melegueta methanolic seed extract, Journal of Tropical Medicine 2014 (2014).

[14] A. Jangra, M. Kwatra, T. Singh, R. Pant, P. Kushwah, S. Ahmed, D. Dwivedi, B. Saroha, M. Lahkar, Edaravone alleviates cisplatin-induced neurobehavioral deficits via modulation of oxidative stress and inflammatory mediators in the rat hippocampus, Eur. J. Pharmacol. 791 (2016) 51-61.

[15] J.P. Spencer, K. Vafeiadou, R.J. Williams, D. Vauzour, Neuroinflammation: modulation by flavonoids and mechanisms of action, Mol. Aspects Med. 33 (1) (2012) 83-97.

[16] D.L. Krause, N. Müller, Neuroinflammation, microglia and implications for antiinflammatory treatment in Alzheimer's disease, International Journal of Alzheimer's Disease 2010 (2010).

[17] E.G. McGeer, P.L. McGeer, Inflammatory processes in Alzheimer's disease, Prog. Neuro-Psychopharmacol. Biol. Psychiatry 27 (5) (2003) 741-749. 
[18] K. Saijo, B. Winner, C.T. Carson, J.G. Collier, L. Boyer, M.G. Rosenfeld, F.H. Gage, C.K. Glass, A Nurr1/CoREST pathway in microglia and astrocytes protects dopaminergic neurons from inflammation-induced death, Cell 137 (1) (2009) 47-59.

[19] M.K. McCoy, M.G. Tansey, TNF signaling inhibition in the CNS: implications for normal brain function and neurodegenerative disease, Journal of neuroinflammation 5 (1) (2008) 45.

[20] S. Soldano, C. Pizzorni, S. Paolino, A.C. Trombetta, P. Montagna, R. Brizzolara, B. Ruaro, A. Sulli, M. Cutolo, Alternatively activated (M2) macrophage phenotype is inducible by endothelin-1 in cultured human macrophages, PLoS ONE 11 (11) (2016), e0166433.

[21] P. Rangarajan, A. Karthikeyan, S. Dheen, Role of dietary phenols in mitigating microglia-mediated neuroinflammation, NeuroMol. Med. 18 (3) (2016) 453-464.

[22] Q. Xia, Q. Hu, H. Wang, H. Yang, F. Gao, H. Ren, D. Chen, C. Fu, L. Zheng, X. Zhen, Induction of COX-2-PGE2 synthesis by activation of the MAPK/ERK pathway contributes to neuronal death triggered by TDP-43-depleted microglia, Cell Death Dis. 6 (3) (2015) e1702.

[23] A. Kulshreshtha, P. Piplani, Current pharmacotherapy and putative diseasemodifying therapy for Alzheimer's disease, Neurological Sciences 37 (9) (2016) 1403-1435.

[24] C. Jang, D.K. Yadav, L. Subedi, R. Venkatesan, A. Venkanna, S. Afzal, E. Lee, J. Yoo, E. Ji, S.Y. Kim, Identification of novel acetylcholinesterase inhibitors designed by pharmacophore-based virtual screening, molecular docking and bioassay, Sci. Rep. 8 (1) (2018) 1-21.

[25] M. Rahman, S. Muhammad, M.A. Khan, H. Chen, D.A. Ridder, H. Müller-Fielitz, B. Pokorná, T. Vollbrandt, I. Stölting, R. Nadrowitz, The $\beta$-hydroxybutyrate receptor HCA 2 activates a neuroprotective subset of macrophages, Nat. Commun. 5 (1) (2014) 1-11.

[26] T.R. Wood, B.J. Stubbs, S.E. Juul, Exogenous ketone bodies as promising neuroprotective agents for developmental brain injury, Dev. Neurosci. 40 (5-6) (2018) 451-462.

[27] R. Ullah, G. Ali, N. Ahmad, M. Akram, G. Kumari, M.U. Amin, M.N. Umar, Attenuation of Spatial Memory in 5xFAD Mice by Halting Cholinesterases, Oxidative Stress and Neuroinflammation Using a Cyclopentanone Derivative, Pharmaceuticals 13 (10) (2020) 318.

[28] S.I. Ahmad, G. Ali, T. Muhammad, R. Ullah, M.N. Umar, A.N. Hashmi, Synthetic $\beta$-hydroxy ketone derivative inhibits cholinesterases, rescues oxidative stress and ameliorates cognitive deficits in 5XFAD mice model of AD, Mol. Biol. Rep. (2020).

[29] P. Anand, B. Singh, A review on cholinesterase inhibitors for Alzheimer's disease, Arch. Pharmacal Res. 36 (4) (2013) 375-399.

[30] D. Secci, S. Carradori, A. Petzer, P. Guglielmi, M. D’Ascenzio, P. Chimenti, D. Bagetta, S. Alcaro, G. Zengin, J.P. Petzer, 4-(3-Nitrophenyl) thiazol-2ylhydrazone derivatives as antioxidants and selective hMAO-B inhibitors: synthesis, biological activity and computational analysis, J. Enzyme Inhib. Med. Chem. 34 (1) (2019) 597-612.

[31] R.C. Brinkerhoff, E. Santa-Helena, P.C. do Amaral, D.d.C. Cabrera, R.F. Ongaratto, P.M. de Oliveira, C.D.R.M. D’Oca, C.A.N. Gonçalves, L.E.M. Nery, M.G.M. D’Oca, Evaluation of the antioxidant activities of fatty polyhydroquinolines synthesized by Hantzsch multicomponent reactions, RSC Advances 9(43) (2019) 24688-24698.

[32] M.F.d. Resende, C.I. Lino, E.M.d. Souza-Fagundes, J.V.P. Rettore, R.B.d. Oliveira, R.A. Labanca, Assessment of anti-diabetic activity of a novel hydrazine-thiazole derivative: in vitro and in vivo method, Brazilian, J. Pharm. Sci. 55 (2019).

[33] D.S. Deng, J. Cai, Stereoselective aldol reactions catalyzed by acyclic amino acids in aqueous micelles, Helv. Chim. Acta 90 (1) (2007) 114-120.

[34] H. Tian, J.-L. Gao, H. Xu, L.-Y. Zheng, W.-B. Huang, Q.-W. Liu, S.-Q. Zhang, Proline-based dipeptides as efficient organocatalysts for asymmetric aldol reactions in brine, Tetrahedron Asymmetry 22 (10) (2011) 1074-1080.

[35] G.L. Ellman, K.D. Courtney, V. Andres Jr, R.M. Featherstone, A new and rapid colorimetric determination of acetylcholinesterase activity, Biochemical pharmacology7(2) (1961) 88-95.

[36] J. Khan, G. Ali, R. Khan, R. Ullah, S. Ullah, Attenuation of vincristine-induced neuropathy by synthetic cyclohexenone-functionalized derivative in mice model, Neurological Sciences (2019) 1-13.

[37] R. Reiserer, F. Harrison, D. Syverud, M. McDonald, Impaired spatial learning in the APPSwe + PSEN1 $\triangle E 9$ bigenic mouse model of Alzheimer's disease, Genes, Brain and Behavior 6 (1) (2007) 54-65.

[38] W. Xu, F. Xu, M.E. Anderson, A.E. Kotarba, J. Davis, J.K. Robinson, W.E. Van Nostrand, Cerebral microvascular rather than parenchymal amyloid- $\beta$ protein pathology promotes early cognitive impairment in transgenic mice, J. Alzheimers Dis. 38 (3) (2014) 621-632.

[39] M. Ayaz, M. Junaid, F. Ullah, F. Subhan, A. Sadiq, G. Ali, M. Ovais, M. Shahid, A. Ahmad, A. Wadood, Anti-Alzheimer's studies on $\beta$-sitosterol isolated from Polygonum hydropiper L, Frontiers in pharmacology8 (2017) 697.

[40] J. Gao, L. Wang, C. Gao, H. Arakawa, G. Perry, X. Wang, TDP-43 inhibitory peptide alleviates neurodegeneration and memory loss in an APP transgenic mouse mode for Alzheimer's disease, Biochimica et Biophysica Acta (BBA)-Molecular Basis of Disease 1866 (1) (2020), 165580.

[41] F. Chu, K. Li, X. Li, L. Xu, J. Huang, Z. Yang, Graphene Oxide Ameliorates the Cognitive Impairment Through Inhibiting PI3K/Akt/mTOR Pathway to Induce Autophagy in AD Mouse Model, Neurochem. Res. 46 (2) (2021) 309-325.

[42] Y. Jiang, K. Li, X. Li, L. Xu, Z. Yang, Sodium butyrate ameliorates the impairment of synaptic plasticity by inhibiting the neuroinflammation in 5XFAD mice, Chem. Biol. Interact. 341 (2021), 109452.

[43] H. Zheng, Q. Zhou, Y. Du, C. Li, P. Xu, L. Lin, J. Xiao, H. Gao, The hypothalamus as the primary brain region of metabolic abnormalities in APP/PS1 transgenic mouse model of Alzheimer's disease, Biochimica et Biophysica Acta (BBA)-Molecular Basis of Disease 1864 (1) (2018) 263-273.

[44] B. Shal, A. Khan, A.U. Khan, R. Ullah, G. Ali, S.U. Islam, I.u. Haq, H. Ali, E.-K. Seo, S. Khan, Alleviation of Memory Deficit by Bergenin via the Regulation of Reelin and Nrf-2/NF-kB Pathway in Transgenic Mouse Model, International journal of molecular sciences 22 (12) (2021) 6603

[45] M.T.S. Trevisan, F.V.V. Macedo, M.v.d. Meent, I.K. Rhee, R. Verpoorte, Screening for acetylcholinesterase inhibitors from plants to treat Alzheimer's disease, Quim. Nova 26 (3) (2003) 301-304.

[46] M.M. Bradford, A rapid and sensitive method for the quantitation of microgram quantities of protein utilizing the principle of protein-dye binding, Analytical biochemistry72(1-2) (1976) 248-254.

[47] G.L. Ellman, Tissue sulfhydryl groups, Archives of biochemistry and biophysics82 (1) (1959) 70-77.

[48] M. Naveed, S.Z. Khan, S. Zeeshan, A. Khan, B. Shal, A. Atiq, H. Ali, R. Ullah, S. Khan, A new cationic palladium (II) dithiocarbamate exhibits anti-inflammatory, analgesic, and antipyretic activities through inhibition of inflammatory mediators in in vivo models, Naunyn-Schmiedeberg's Arch. Pharmacol. 392 (8) (2019) 961-977.

[49] A. Braca, N. De Tommasi, L. Di Bari, C. Pizza, M. Politi, I. Morelli, Antioxidant principles from bauhinia t arapotensis, J. Nat. Prod. 64 (7) (2001) 892-895.

[50] R. Ullah, G. Ali, F. Subhan, M. Naveed, A. Khan, J. Khan, S.A. Halim, N. Ahmad, Zakiullah, A. Al-Harrasi, Attenuation of nociceptive and paclitaxel-induced neuropathic pain by targeting inflammatory, CGRP and Substance P signaling using 3-Hydroxyflavone, Neurochemistry International (2021) 104981.

[51] G. Ghosh, G. Van Duyne, S. Ghosh, P.B. Sigler, Structure of NF-кB p50 homodimer bound to a кB site, Nature 373 (6512) (1995) 303-310.

[52] R.M. Lane, S.G. Potkin, A. Enz, Targeting acetylcholinesterase and butyrylcholinesterase in dementia, Int. J. Neuropsychopharmacol. 9 (1) (2006) 101-124.

[53] J.S. Choi, M.N. Islam, M.Y. Ali, Y.M. Kim, H.J. Park, H.S. Sohn, H.A. Jung, The effects of C-glycosylation of luteolin on its antioxidant, anti-Alzheimer's disease, anti-diabetic, and anti-inflammatory activities, Arch. Pharmacal Res. 37 (10) (2014) 1354-1363.

[54] A.E. Arrant, N.L. Schramm-Sapyta, C.M. Kuhn, Use of the light/dark test for anxiety in adult and adolescent male rats, Behav. Brain Res. 256 (2013) 119-127.

[55] M. Kruk, K. Tendera, G. Biała, Memory-related effects of cholinergic receptor ligands in mice as measured by the elevated plus maze test, Pharmacol. Rep. 63 (6) (2011) 1372-1382.

[56] R. D'Hooge, P.P. De Deyn, Applications of the Morris water maze in the study of learning and memory, Brain Res. Rev. 36 (1) (2001) 60-90.

[57] K.A. Khan, N. Kumar, P.G. Nayak, M. Nampoothiri, R.R. Shenoy, N. Krishnadas, C. M. Rao, J. Mudgal, Impact of caffeic acid on aluminium chloride-induced dementia in rats, J. Pharm. Pharmacol. 65 (12) (2013) 1745-1752.

[58] Y.-Y. Fan, Q.-L. Cai, Z.-Y. Gao, X. Lin, Q. Huang, W. Tang, J.-H. Liu, APOE $\varepsilon 4$ allele elevates the expressions of inflammatory factors and promotes Alzheimer's disease progression: A comparative study based on Han and She populations in the Wenzhou area, Brain Res. Bull. 132 (2017) 39-43.

[59] G. Bahn, D.-G. Jo, Therapeutic approaches to Alzheimer's disease through modulation of NRF2, NeuroMol. Med. 21 (1) (2019) 1-11.

[60] M.B. Colović, D.Z. Krstić, T.D. Lazarević-Pašti, A.M. Bondžić, V.M. Vasić, Acetylcholinesterase inhibitors: pharmacology and toxicology, Curr. Neuropharmacol. 11 (3) (2013) 315-335.

[61] S.A. Gany, S.C. Tan, S.Y. Gan, Antioxidative, anticholinesterase and antineuroinflammatory properties of Malaysian brown and green seaweeds, International Journal of Industrial and Manufacturing Engineering 8 (11) (2015) 1269-1275.

[62] E.E. Spangenberg, K.N. Green, Inflammation in Alzheimer's disease: lessons learned from microglia-depletion models, Brain Behav. Immun. 61 (2017) 1-11.

[63] V. Gupta, R. Guleri, M. Gupta, N. Kaur, K. Kaur, P. Kumar, M. Anand, G. Kaur, P. K. Pati, Anti-neuroinflammatory potential of Tylophora indica (Burm. f) Merrill and development of an efficient in vitro propagation system for its clinical use, PLoS ONE 15 (3) (2020), e0230142.

[64] G. Deng, C. Wu, X. Rong, S. Li, Z. Ju, Y. Wang, C. Ma, W. Ding, H. Guan, X. Cheng, Ameliorative effect of deoxyvasicine on scopolamine-induced cognitive dysfunction by restoration of cholinergic function in mice, Phytomedicine 63 (2019), 153007.

[65] V.I. Turiiski, A.D. Krustev, V.N. Sirakov, D.P. Getova, In vivo and in vitro study of the influence of the anticholinesterase drug galantamine on motor and evacuative functions of rat gastrointestinal tract, Eur. J. Pharmacol. 498 (1-3) (2004) 233-239.

[66] R. Yang, Q. Wang, L. Min, R. Sui, J. Li, X. Liu, Monosialoanglioside improves memory deficits and relieves oxidative stress in the hippocampus of rat model of Alzheimer's disease, Neurological Sciences 34 (8) (2013) 1447-1451.

[67] T. Jiang, Q. Sun, S. Chen, Oxidative stress: A major pathogenesis and potential therapeutic target of antioxidative agents in Parkinson's disease and Alzheimer's disease, Prog. Neurobiol. 147 (2016) 1-19.

[68] M. Valko, D. Leibfritz, J. Moncol, M.T. Cronin, M. Mazur, J. Telser, Free radicals and antioxidants in normal physiological functions and human disease, The international journal of biochemistry \& cell biology 39 (1) (2007) 44-84.

[69] B. Halliwell, Free radicals and antioxidants: updating a personal view, Nutr. Rev. 70 (5) (2012) 257-265.

[70] C.B. Pocernich, D.A. Butterfield, Elevation of glutathione as a therapeutic strategy in Alzheimer disease, Biochimica et Biophysica Acta (BBA)-Molecular Basis of Disease 1822 (5) (2012) 625-630. 
[71] R.E. González-Reyes, M.O. Nava-Mesa, K. Vargas-Sánchez, D. Ariza-Salamanca, L. Mora-Muñoz, Involvement of astrocytes in Alzheimer's disease from a neuroinflammatory and oxidative stress perspective, Front. Mol. Neurosci. 10 (2017) 427.

[72] J.H. Suh, S.V. Shenvi, B.M. Dixon, H. Liu, A.K. Jaiswal, R.-M. Liu, T.M. Hagen, Decline in transcriptional activity of Nrf2 causes age-related loss of glutathione synthesis, which is reversible with lipoic acid, Proc. Natl. Acad. Sci. 101 (10) (2004) 3381-3386.

[73] T. Ali, T. Kim, S.U. Rehman, M.S. Khan, F.U. Amin, M. Khan, M. Ikram, M.O. Kim, Natural dietary supplementation of anthocyanins via PI3K/Akt/Nrf2/HO-1 pathways mitigate oxidative stress, neurodegeneration, and memory impairment in a mouse model of Alzheimer's disease, Mol. Neurobiol. 55 (7) (2018) 6076-6093.

[74] A. Wong, H.J. Lüth, W. Deuther-Conrad, S. Dukic-Stefanovic, J. Gasic-Milenkovic, T. Arendt, G. Münch, Advanced glycation endproducts co-localize with inducible nitric oxide synthase in Alzheimer's disease, Brain Res. 920 (1-2) (2001) 32-40.

[75] W.S.T. Griffin, J.G. Sheng, G.W. Roberts, R.E. Mrak, Interleukin-1 expression in different plaque types in Alzheimer's disease: significance in plaque evolution, J. Neuropathol. Exp. Neurol. 54 (2) (1995) 276-281.

[76] M. van Gijsel-Bonnello, K. Baranger, P. Benech, S. Rivera, M. Khrestchatisky, M. de Reggi, B. Gharib, Metabolic changes and inflammation in cultured astrocytes from the 5xFAD mouse model of Alzheimer's disease: alleviation by pantethine, PLoS ONE 12 (4) (2017), e0175369.

[77] G.-H. Cui, H.-D. Guo, H. Li, Y. Zhai, Z.-B. Gong, J. Wu, J.-S. Liu, Y.-R. Dong, S.X. Hou, J.-R. Liu, RVG-modified exosomes derived from mesenchymal stem cells rescue memory deficits by regulating inflammatory responses in a mouse model of Alzheimer's disease, Immunity \& Ageing 16 (1) (2019) 10.

[78] H. Akiyama, S. Barger, S. Barnum, B. Bradt, J. Bauer, G.M. Cole, N.R. Cooper, P. Eikelenboom, M. Emmerling, B.L. Fiebich, Inflammation and Alzheimer's disease, Neurobiol. Aging 21 (3) (2000) 383-421.

[79] E.G. McGeer, P.L. McGeer, Neuroinflammation in Alzheimer's disease and mild cognitive impairment: a field in its infancy, J. Alzheimers Dis. 19 (1) (2010) 355-361.
[80] C. Schwab, A. Klegeris, P.L. McGeer, Inflammation in transgenic mouse models of neurodegenerative disorders, Biochimica et Biophysica Acta (BBA)-Molecular Basis of Disease 1802 (10) (2010) 889-902.

[81] M.J. Sharman, G. Verdile, S. Kirubakaran, C. Parenti, A. Singh, G. Watt, T. Karl, D. Chang, C.G. Li, G. Münch, Targeting Inflammatory Pathways in Alzheimer's Disease: A Focus on Natural Products and Phytomedicines, CNS drugs 33 (5) (2019) 457-480.

[82] W.J. Lukiw, NF-кB-regulated, proinflammatory miRNAs in Alzheimer's disease, Alzheimer's research \& therapy 4 (6) (2012) 47.

[83] K.R. Stover, M.A. Campbell, C.M. Van Winssen, R.E. Brown, Analysis of motor function in 6-month-old male and female 3xTg-AD mice, Behav. Brain Res. 281 (2015) 16-23.

[84] M. Bhanumathy, M. Harish, H. Shivaprasad, G. Sushma, Nootropic activity of Celastrus paniculatus seed, Pharm. Biol. 48 (3) (2010) 324-327.

[85] G. Biala, M. Kruk, Cannabinoid receptor ligands suppress memory-related effects of nicotine in the elevated plus maze test in mice, Behav. Brain Res. 192 (2) (2008) 198-202.

[86] A. Manasa, S. Karimulla, M. Gobinath, Ameliorative effect of Cleome gynandra Linn against scopolamine induced amnesia in mice, International Journal of Research in Pharmaceutical Sciences 8 (4) (2017) 642-649.

[87] F. Vasilopoulou, S. Rodríguez-Arévalo, A. Bagán, C. Escolano, C. Griñán-Ferré M. Pallàs, Disease-modifying treatment with I2 imidazoline receptor ligand LSL60101 in an Alzheimer's disease mouse model: a comparative study with donepezil, Br. J. Pharmacol. 178 (15) (2021) 3017-3033.

[88] N. Nazir, N. Karim, H. Abdel-Halim, I. Khan, S.F. Wadood, M. Nisar, Phytochemical analysis, molecular docking and antiamnesic effects of methanolic extract of Silybum marianum (L.) Gaertn seeds in scopolamine induced memory impairment in mice, J. Ethnopharmacol. 210 (2018) 198-208.

[89] J. Hui, G. Feng, C. Zheng, H. Jin, N. Jia, Maternal separation exacerbates Alzheimer's disease-like behavioral and pathological changes in adult APPswe/ PS1dE9 mice, Behav. Brain Res. 318 (2017) 18-23. 